\title{
Potential Output in Theory and Practice: A Revision and Update of Okun's Original Method
}

\section{Claudia Fontanari, Antonella Palumbo and Chiara Salvatori $^{1}$}

\section{Working Paper No. 93}

\author{
March 31 ${ }^{\text {st }}, 2019$
}

\begin{abstract}
This paper challenges the mainstream view of potential output, and enquires into the supposed effects of Great Recession on potential growth. We identify in the demand-led growth perspective a more promising theoretical framework both to define the notion and to gauge the long-term effects of a demand slow down. Based on the poor reliability of standard estimates of potential output, we also propose an alternative calculation.

This is based on an update of Arthur M. Okun's original method for estimating potential output, which, differently from the estimation methods currently in use, does not rely on the notion of NAIRU, thus being immune to its theoretical and empirical shortcomings. Our calculation, based on a re-estimation of Okun's Law on US quarterly data, shows both how far an economy generally operates from its production possibilities, and how much potential growth is affected by the actual growth of demand over time.

These wide margins for expansion of actual and potential output growth imply that a determined policy of demand expansion would create, given time, the very capacity that justifies it.
\end{abstract}

\footnotetext{
${ }^{1}$ Roma Tre University.
}

We wish to thank Thomas Ferguson, Jie Chen and Alessia Naccarato for useful comments and invaluable help. Financial support by the Institute for New Economic Thinking (INET) is gratefully acknowledged. 
JEL Codes: E60; E23; E24; O40; E11; E12; C22

Keywords: potential output; Okun's law; unemployment; demand-led growth 


\section{Introduction: Potential Output After the Fall}

There is at least one respect in which the Great Crisis of 2007-09 and its turbulent aftermath have managed to undermine, if only in part, the certainties of mainstream economics, and this is the damage that the crisis has brought about to perceptions of the future prospects of long-term growth. According to most consensus macro models and textbooks, a demand shock should have only temporary effects on production. It should not affect potential output. Since the crisis, however, virtually all empirical assessments of actual and potential output growth show a remarkable slow down. ${ }^{2}$

This actually represents a challenge to deep-rooted theoretical beliefs. Some purely supply-side explanations have indeed been attempted, which identify factors that may have produced a slow down in labor force participation and productivity independently of the Great Recession. The main candidate, in this respect, is the ageing of population, but also structural and institutional rigidities (and the parallel absence of incisive structural reforms) are often invoked as possible culprits. The mystery in this kind of interpretation, as recently remarked by Krugman (2018), is the perfect temporal coincidence between this (assumedly independent) deterioration in supply factors and the unfolding of the Great Recession. Nor, as maintained by Ball (2014) and Fatas (2018), is it easy to explain why the greatest losses of potential output are estimated exactly for those economies hit hardest by the crisis.

Indeed, the idea that a big shock in demand may have somehow affected supply factors, long held by the authors that have proposed the notion of hysteresis, seems, in the face of evidence, to have made its way even in unexpected quarters. Literature produced on European institutions, for example, in both official publications and in research papers, often admits that high unemployment and falls in demand tend to generate slower accumulation of capital, deterioration in labor input quality, and discourage workers. (European Commission 2009; European Central Bank 2011; D'Auria et al. 2010; Anderton et al. 2014).

The possibility should however be considered that these estimates of a slowdown in potential output growth do not reflect any real process at all. Potential output is a purely theoretical construct, with no immediate empirical counterpart; it could be that the problem lies entirely with the way in which potential output and the potential path of growth are estimated. Indeed, much critical literature has been highlighting for a long time many limitations of standard estimates of potential output and its cognate notion, the Non-Accelerating Inflation Rate of Unemployment (NAIRU), particularly the

\footnotetext{
${ }^{2}$ See, e.g., Ball (2014), which calculates for a sample of 23 OECD countries an average 8 percent loss of potential output due to the crisis, with some countries like Greece having lost as much as 30 percent. For the USA, Reifschneider et al. (2015) estimate a 6 percent loss with respect to the pre-crisis trend, while the U.S. Congressional Budget Office (CBO 2014), by comparing its own estimates for 2017 produced at different dates, notices a 7.3 percent loss of potential output in the 2014 estimate with respect to the 2007 estimate.
} 
disproportionate weight that the trend of actual output has in the estimation exercises (or, equivalently, the weight that the trend of the actual rate of unemployment has in the estimation of the NAIRU). ${ }^{3}$ The heavy downward revisions of estimates of potential output since the crisis would thus simply reflect the slowdown of actual growth.

Suppose we could assume for a moment that this line of criticism was correct and that we could identify some alternative estimate of potential output on which basis it could be maintained that the deep recession that so many economies have endured has not altered noticeably their potential paths nor damaged growth's future prospects. Let us imagine instead that the dismal story of the recent years could be interpreted as the opening up of an enormous (negative) output gap. Given time, the gap will be closed and the path of pre-growth crisis resumed. The challenge to received theory, in this case, would be no less formidable. In a theoretical context in which actual output is assumed to oscillate around potential due to the existence of equilibrating mechanisms that correct any deviations brought about by demand, it would not be easy to explain how a demand shock has managed to produce such a deep and persistent deviation of actual output from the potential path. What has made the equilibrating mechanisms so utterly inoperative for so long an interval of time? How could the actual rate of unemployment linger so persistently far from equilibrium? What would be the theoretical and practical usefulness of an "equilibrium" magnitude which proves to be so feeble an attractor of actual variables?

Not to speak of the policy implications of such a fact. If such a huge gap did actually open up then the scope for expansionary monetary and fiscal policy would be enormous, the more so in those countries of Southern Europe so heavily hit by a double recession and still unable to recover, to this day, the levels of production of 2007. The whole architecture of the European fiscal rules should be heavily revised, to say the least.

Two different kinds of questions are thus implied in the discussion of what Paul Krugman has named "the Great Shortfall", i.e. the decline in output growth rates that has followed the Great Recession. The first one is the difficulty of mainstream economic theory in coming to terms with the phenomenon in a meaningful way, be it interpreted as a decline in potential growth or not, and the theoretical alternatives to it. The second question is the tenuous reliability of the standard estimates of potential output, and the possibility of envisaging some different measures. After all, assessing what happened to potential output seems a quite interesting question.

We suggest that a more promising theoretical perspective to address these questions is to be found in the theory of demand-led growth, according to which aggregate demand is the main constraint both on the level of production and its growth over time.

3 See Solow (1986) for an early criticism to the actual meaning of the estimated NAIRU and below, section 1 , for a review of the literature. 
According to this perspective, demand determines the level of activity and thus the level of capacity utilization in the short period, when productive capacity is given, while in the long period it influences the very pace at which productive resources accumulate, and may also affect the velocity of adoption of technical innovations.

From such a perspective (which, albeit with different accents, is at the basis of many recent contributions dealing with the effects of the crisis, such as Ball, 2014; Fazzari et al., 2018; Girardi et al., 2017; Storm, 2017; Dosi et al., 2018; Fatás, 2018), the abovementioned dilemma regarding the Great Shortfall has a straightforward explanation. The prolonged crisis in demand may well have produced both a loss of actual output with respect to its potential level and a downward displacement of the whole potential growth path itself. No powerful equilibrating mechanisms ensure, in this view, automatic correction of deviations from the normal use of resources, so that there is no theoretical difficulty in accounting for big negative output gaps. At the same time, as a consequence of persistent underutilization, the pace of accumulation of resources slows down and declines: capital shrinks through negative net investment, participation to the labor force falls, long spells of unemployment deteriorate labor quality; thus affecting, after a while, not only actual production but the very growth prospects.

Starting from this alternative theoretical perspective, this paper addresses the empirical question of how to measure, in an acceptable and not too arbitrary way, both the deviations of actual output from potential and the changes in the potential path. Actually, as the literature reviewing the limitations of the standard estimates of potential output has already shown, this is hardly a purely empirical question. ${ }^{4}$ On the contrary, estimation methods are heavily influenced by the underlying theory, and many of the unsatisfying characteristics and puzzling results of the standard estimates, as will be briefly recalled in section 1, are precisely the product of dubious theoretical premises. A different theoretical perspective also requires, in our view, that different estimation methods are envisaged. Potential output should be regarded (and measured) as the output that could be obtained, in any given situation, by fully using the available resources, thus allowing for actual output to considerably deviate from it in cases of deep recessions. Current estimation methods do instead regard, directly or indirectly, potential output as coincident with the trend of actual output, thus implicitly assuming that actual output can never deviate too much from potential, but rather fluctuates around it.

As an attempt in this direction, we propose here a method of estimation of potential output that revisits and updates the method originally proposed by Arthur M. Okun in the $1960 \mathrm{~s}$, which has in our view the distinct advantage of relying on a theoretical notion of potential output that is entirely independent of the NAIRU, being rather connected to (although not coincident with) Keynes's notion of full employment output.

4 The question has been treated in Palumbo (2015). See section 1 for more references to this literature. 
The theoretical and empirical characteristics of Okun's original method are discussed in Section 2.

As is known, a necessary ingredient in Okun's calculation of potential output is represented by Okun's Law, the empirical correlation between changes in unemployment and output growth. We will review, in Section 3, the empirical literature on Okun's Law that has continued to flourish in recent years, while our own estimate of Okun's Law on US data will be presented in Section 4.1. As an original contribution of this paper, by developing a hint that is to be found in Okun (1962), we improve the fit of Okun's Law by allowing for changes in the unemployment-output relationship according to the level of unemployment. We then use the estimated coefficients to perform our own calculation of the series of potential output, which in section 4.2 is presented and compared with the U.S. Congressional Budget Office estimates. This comparison highlights the very different results, as regards the size of the output gaps, that our different theoretical perspective and our methodology entail with respect to standard estimates.

On reviewing the meaning and limits of our measure of potential output, we notice that Okun's estimates are based on the hypothesis that installed capacity and technical knowledge are the same as those actually observed. This implies that the trend of potential output, so calculated, is strongly affected by the way the actual level and growth of demand in each of the previous periods has influenced the accumulation of resources and the growth in productivity. This prompts us to try a different exercise. In section 5, we compare the just-obtained estimated path of demand-determined potential output with a benchmark path, which represents, over the same period, the growth that potential output might have undergone, if only demand had been persistently strong enough at all points of time. We label such benchmark path as the "high-demand potential path."

Section 6 compares our two different notions of potential output and concludes by drawing some implications for policy.

\section{Problems and puzzles in the standard estimates of potential output}

As a rapidly growing critical literature has been pointing out in recent years, there are at least two highly problematic aspects to the estimates of potential output routinely performed by governments, central banks, supra-national and international institutions. The first is the above-mentioned 'excess sensitivity' that the estimates show to changes in the trend of actual output; the second has to do with their volatility and lack of robustness to small changes in specification of the models.

This second characteristic is no less problematic than the first, given that the sign and 
size of output gaps are a very sensitive policy issue. ${ }^{5}$ Output gaps contribute crucially to determination of both monetary policy under inflation targeting and fiscal policy. Member states of the European Union, for example, according to the 2012 revision to the Stability and Growth Pact, have to comply with a medium-term objective (a zero structural public budget) calculated on the basis of potential output. ${ }^{6}$ Lack of robustness and volatility of estimates are thus very unfortunate. They show in output gaps that either change sign too frequently or change size across estimates performed by different institutions, often differing only for a limited number of hypotheses (on the values of some parameters) while sharing the same estimation method. In the European Union, this lack of robustness has generated a debate among institutions (notably, national governments and the European Commission; see for an account Ciucci and Zoppè 2016) on the possibility that the Commission's assessments of the Member States' compliance with fiscal rules are biased by estimates of dubious reliability. ${ }^{7}$

As shown in Palumbo (2015), both problematic characteristics of estimates are directly connected to the theoretical definition of potential output on which estimation methods are based.

Potential output is generally defined as the maximum level of output that an economy can attain without producing inflationary pressures. According to mainstream theory, this is the level of output corresponding to equilibrium in the labor market. In practical applications, the latter is usually identified with the NAIRU, thus allowing for imperfections and rigidities that give rise to a non-efficient equilibrium. ${ }^{8}$ Entirely determined by supply factors and institutional variables ${ }^{9}$, the NAIRU is the only rate of unemployment at which inflation neither accelerates nor decelerates. In this theoretical perspective, not only is potential output a desirable target for the economy, it also

\footnotetext{
5 See the following remark in Cotis et al. (2004, p. 16): "estimates of output gaps have sometimes been systematically biased and reliance on them have arguably led to serious policy mistakes."

6 In addition, estimated potential growth sets the maximum pace at which public expenditure may grow.

7 The Commission's assessments are based on official estimates that are produced by member states according to a common methodology established by the Output Gap Working Group (OGWG) of the Economic Policy Committee, and by means of an estimation model provided by the European Commission itself. The EU typically estimates smaller output gaps with respect to other institutions' models. In a note of 2015, the Italian Parliamentary Budget Office showed that, if OECD estimates of potential output were substituted for the official EU estimates, Italy would have realized its medium term objective of zero structural budget already by 2014 (see Fioramanti et al. 2015, p. 27). Similarly, the Italian Government, in its 2016 Stability Programme, showed how a slightly modified estimation model would imply as a result Italy's attainment of the objective in 2015 (which, according to official estimates, has never been realized until now, early 2019). The problem, also raised by official representatives of other seven member states, has been partly recognized even by the Commission itself (see for example EC 2016). In September 2017 a process of revision of the common estimation methodology has been initiated within the OGWG, aimed to allow member states to request some minor adjustments on the basis of country-specific features.

8 Although based on an 'imperfectionist' conception of the labor market, and allowing for inefficient outcomes of the market mechanisms, the NAIRU defined in new-Keynesian models is indistinguishable for practical purposes from the natural rate of unemployment à la Friedman. Both kinds of models postulate a tendency towards an equilibrium rate of unemployment at which inflation stays constant (which implies that they are estimated by means of the same reduced-form equation). See Cross (1995); Pesaran and Smith (1995), Ball and Mankiw (2002). In both kinds of models, the same policies are advocated, namely supply policies flexibilizing the labor market, supposedly able to reduce permanently the equilibrium rate of unemployment (Stirati and Paternesi Meloni 2018).

9 The exception being represented by models with partial or full hysteresis.
} 
represents the level of output that the system tends to realize averaging across fluctuations. In the models without hysteresis, aggregate demand plays in fact only the limited role of producing temporary fluctuations of actual output around its trend, with positive output gaps (induced by positive demand shocks) determining accelerating inflation, and negative output gaps decelerating inflation.

Based on this theoretical consensus, the estimation methods that are currently used by national and international institutions are built on one of the following three principles (or some combination of the three) ${ }^{10}$ :

a. either potential output is simply estimated as trend output, through the application of statistical univariate filters to the series of actual output;

b. or the NAIRU is estimated by using inflation data, usually by means of a Phillips curve, on the theoretical principle that positive (negative) inflation changes must correspond to negative (positive) unemployment gaps, and then output gaps are computed on the basis of such unemployment gaps;

c. or an attempt is made to estimate directly the evolution over time of supply factors, on the theoretical principle that growth of potential output is exclusively a supply-side phenomenon, by means of an explicit model of the economy. This class of models includes the production function approach, which obtains potential output by applying an aggregate production function to the time series of estimated potential inputs and potential total factor productivity (TFP). The majority of estimation models of the main international institutions are based nowadays on such a method. ${ }^{11}$

All types of models proceed by estimating over a relatively long stretch of macroeconomic data - usually at least 20 years - and then projecting the results forward for a number of years. ${ }^{12}$

Class $a$ models are often referred to as 'statistical methods' while classes $b$ and $c$ are often styled as 'economic methods' because of their reliance on assumed theoretical relations. But in fact the statistical methods are anything but 'theory-free' (as they are sometimes defined, see for example Bassanetti et al. 2010, p.7; see also Oksanen 2018, p. 5), being instead based on the purely theoretical presumption that actual output tends to fluctuate around potential output. In this class of methods, actual output is prevented by construction from deviating other than temporarily from potential output, with the greater or lesser adherence between the two series entirely depending on the statistical

\footnotetext{
${ }^{10}$ For surveys on potential output estimation methods see for example Ladiray et al. (2003); Horn et al. (2007); Bassanetti et al. (2010); Anderton et al. (2014); Alichi et al. (2017).

11 Other methods in this class are those based on structural systems of simultaneous equations. These include the structural VAR models (sVARs), in which all variables are regarded as endogenous and the economy can be affected by more than one type of disturbance (Blanchard and Quah 1989, Horn et al. 2007), and the DSGE models (Vetlov et al. 2011). The former identifies different types of shocks and assume that only structural shocks affect potential; the latter estimate potential output by calibrating a DSGE model on the economy then simulating a path without demand disturbances. In both cases, the high number of unknown parameters and the difficult identification of the nature of disturbances imply many arbitrary assumptions and high sensitivity of the estimates to model specification (Alichi et al. 2015).

${ }_{12}$ The EC projects potential growth 2 years ahead, while the CBO 10 years ahead.
} 
definition of cycle and trend.

The literature identifies two main drawbacks of the statistical methods (see for example Anderton et al. 2014): firstly, because the trend is stochastic and thus allowed to vary in each period, the decomposition of the series between trend, cyclical, and accidental components is arbitrary with the result that different filters may produce remarkably different output gaps; moreover, since positive and negative output gaps have a purely statistical definition, they usually prove uncorrelated to changes in inflation (Giorno et al. 1995). ${ }^{13}$

The greater adherence to the relations between variables prescribed by theory explains why economic methods are generally preferred. Class $b$ models rely on different methods to estimate the NAIRU ${ }^{14}$ (see for example Apel e Jansson, 1999a, 1999b; Gordon 1997; Lee 2000; Fabiani e Mestre 2000, 2004; Boone et al. 2003). ${ }^{15}$ Potential output in terms of the NAIRU is calculated, for example, by means of Okun's Law. Frequently, calculation of the NAIRU based on inflation data is combined with filtering techniques, giving rise to so-called 'multivariate filters' for estimating potential output that represent a mixture of statistical and economic methods.

Estimates of the NAIRU play a crucial role in all economic methods, including class $c$ methods. We refer here to Palumbo (2015), which summarizes other critical literature, reviews the main estimation models of the NAIRU, and shows how, though using different specifications, they all define the unemployment gaps as temporary deviations that tend to be symmetrical over the whole estimation period. This implies that the unobservable NAIRU, defined itself as a time-varying stochastic process, is in fact estimated as the trend of the actual rate of unemployment, while negative and positive unemployment gaps, instead of having an arbitrary statistical definition, are correlated to observed changes in inflation.

This kind of procedure has some interesting consequences on the actual content of the estimates of the NAIRU and the unemployment gaps. In the first place, due to the theoretical assumption that inflation changes may only account for cyclical deviations of the actual unemployment rate from the NAIRU, any persistent observed change in the average level of actual unemployment is automatically interpreted as meaning that

\footnotetext{
13 A further drawback is the so-called "end-point problem" (Billmeier, 2009), i.e. the poor reliability of univariate filters at the end of samples (see also Anderton et al 2014, p. 8; Richardson et al. 2000, p. 37; Bassanetti et al. 2010, p. 7).

14 Some estimation models, such as the one of the European Commission, refer to the NAWRU (nonaccelerating-wage rate of unemployment) rather than the NAIRU. The difference between the two notions has no impact on gap estimation.

15 Also models for estimation of the NAIRU may be classified in different types (see for example Fabiani e Mestre 2000; Richardson et al. 2000). While statistical univariate filters extract the NAIRU from the trend of the actual rate of unemployment, multivariate filters typically correct the result by using inflation data. Most estimation models are based on theoretical relations, such as a reduced-form Phillips curve or, in some cases, a structural model of the labor market (Gordon 1997; Boone et al. 2003).
} 
the NAIRU has changed. ${ }^{16}$ In the 1990s, as noted by Solow (2000), this produced the puzzling result of rising estimated NAIRUs in many European countries that had been adopting those flexibilization measures of the labor market that according to theory should, if anything, reduce the NAIRU. ${ }^{17}$ In the second place, attempts to take into account changes in the signs and the sizes of inflation changes to determine unemployment gaps implies generally that the estimated NAIRU is very volatile (Richardson et al. 2000; Franz 2005). This depends on the fact that no regular shortperiod relationship holds between unemployment changes and inflation changes in the data (Beckerman and Jenkinson 1986; Galbraith 1997; for some examples of uncertain or variable relation see Gordon 1970; Musso et al. 2009; Peach et al. 2011), despite the deeply-rooted theoretical belief that such a regular relation exists. In reality, not only does inflation show widely different reactivity to changes in unemployment in different epochs, but the relevance of other determinants often blurs or at times even subverts the expected relationship. ${ }^{18}$ This implies that empirical analyses, when models are not constrained a priori to conform to a vertical Phillips curve, tend rather to detect in data, if anything, a traditional decreasing Phillips curve, (Blanchard 2016, Franz 2005, Schreiber and Wolters 2007) ${ }^{19}$. In recent years the estimated Phillips curves are supposedly characterized by so flat a slope ${ }^{20}$ that this raises questions about the very idea that a relationship exists between inflation and unemployment, let alone that a true NAIRU exists. ${ }^{21}$

In the face of these difficulties, which have recently brought Solow $(2018$, p. 423) to state that "there is no well-defined natural rate of unemployment, either statistically or conceptually", the models currently used by official institutions for estimation of potential output do instead rely on the NAIRU and impose specifications that guarantee

\footnotetext{
${ }^{16}$ Also in this case, the greater or lesser adherence of the series of the estimated NAIRU to that of actual unemployment depends on the particular model adopted or specific assumptions on parameters.

17 Some ex-post theoretical justification, of course, is always possible. As noted by Galbraith 1997: «In general, the estimated NAIRU in a variety of studies has tracked the actual unemployment rate sluggishly. When unemployment rises, analysts tend to discover that the demographic characteristics of workers are deteriorating, or that the job-wage and wage-price dynamic has become unstable. And then the unemployment rate drifts down again, those flaws mysteriously begin to disappear, and a lower NAIRU is estimated».

${ }_{18}$ The relevance of other factors (such as oil prices, prices of imports in general, expectations of inflation) is often invoked to justify the disappointingly low correlation between inflation changes and the estimated unemployment gaps. See for example ECB (2011); Jasova et al. (2018).

19 Specifically, Schreiber and Wolters (2007) identify a long-run decreasing Phillips curve on German quarterly data (1977-2002); while Franz (2005), analyzing similar data (Germany, 1972-2002), asserts the instability of the relation and the non-existence of a single vertical Phillips curve. Blanchard (2016) finds a decreasing long-run Phillips curve on US quarterly data (1960-2014), also noting a flattening of the slope after the 1980 .

${ }^{20}$ Martin (2011, p. 51) reports findings of Treasury economists for the UK (1997-2009), noting that "when attention was confined to the period of low inflation since 1997, the relationship disappeared, or worse, was the wrong way round". Many analyses that use the standard definition of a long-period vertical Phillips curve assuming the existence of the NAIRU, find evidence of a flattening of the slope of the (short-period) Phillips curve. This is especially true for advanced countries after the Great Recession, according to Jasova et al. (2018). The IMF, in its World Economic Outlook of April 2006, reports evidence of a very flat relationship on data for several countries (Australia, Canada, France, Germany, Italy, Japan, the United Kingdom, the United States) over the two previous decades. Also Peach et al. (2011), detect such a flattening for the USA since the mid-1980s.

${ }^{21} \mathrm{See}$, in this regard, the discussion on the theoretical and empirical limits of Friedman's notion of 'natural rate of unemployment' in Review of Keynesian Economics, issue 4 of 2018.
} 
a vertical Phillips curve. The consequent volatility of estimates is then dealt with by using some smoothing procedure which yields a less erratic NAIRU, at the cost of lowering somehow the correlation between unemployment gaps and inflation changes (Billmeier, 2009). But what cannot be avoided is that estimated unemployment gaps prove very sensitive to small changes in specification and in the value of parameters (Richardson et al. 2000).

Thus, the attempt to calculate potential output by making use of inflation data does not emancipate potential output from being defined and measured, in practice, as the trend of observed actual output, as is straightforward in the case of multivariate statistical filters. But it also adds to potential output estimates the characteristic uncertainty and volatility that are so often noted even by the very institutions routinely offering estimates of potential output.

Estimation methods of class $c$ do not change the actual content of the estimates in any relevant respect. In the widely used production function approach, the time series of the potential inputs (potential labor, potential capital, and potential total factor productivity, TFP) needed to estimate potential output are in fact obtained in practice as filtered series of actual employment, the actual capital stock, and the TFP that results by regressing actual output on actual inputs. ${ }^{22}$ Especially relevant is the fact that the series of the potential labor input is obtained by correcting the filtered series of actual labor force with the estimated NAIRU. As a result, potential output continues to represent basically the trend of actual output, although calculated, this time, through a much more indirect and complex procedure, and not by the mere application of a statistical filter to the actual output series. The crucial role of the NAIRU in the estimation procedure entails that the above mentioned uncertainty and volatility also affect the estimates of the output gaps obtained through the production function approach.

To sum up, it is clear that current estimation methods do not go much further than calculating potential output as some sort of (elaborate) moving average of the actual one, which explains why the Great Recession, having produced negative effects on the trend of actual output, also has had effects on potential output estimates. From the policy point of view, this basic characteristic of estimation methods implies that no very big output gaps tend to open up, even in deep recessions, due to downward revisions in potential output estimates. ${ }^{23}$ Which generally reduces, consistently with the mainstream policy attitude, the need for and the scope of expansionary demand policies. ${ }^{24}$

\footnotetext{
${ }^{22}$ For comparisons of the models applied by the various institutions to obtain potential inputs, which differ in some minor respects, see for example Cotis et al. (2005); Anderton et al. (2014); Fioramanti et al (2015). 23 As noted above, the slight differences across estimates of different institutions produce some differences in the size of the output gaps. See for example Fioramanti et al. (2015), Ciucci and Zoppè (2016).

24 See for example Solow (2000), who goes as far as maintaining that procedures for gap estimation tend to be a "dogmatic exercise" (p.10). Cf. also Costantini (2015).
} 


\section{Searching for alternative measures: a re-assessment of Okun's method}

The above account makes it clear that standard estimation methods are both empirically and theoretically ill-suited to evaluate how far the Great Recession has affected the path of potential growth and/or how deep a gulf it has opened between actual and potential output. Rather than attempting to measure the evolution over time of the production possibilities of an economy, these methods simply deduce them from actual realizations, on the unproven assumption that the two can never be too far apart.

In the following we venture to propose an alternative method for the estimation of potential output that is both immune to some of the most obvious limitations of standard estimation methods and more consistent with our theoretical premises, i.e. with the idea that both actual and potential output are affected by the evolution of aggregate demand. Though aware of the inevitable arbitrariness of some of our assumptions, and thus the highly imperfect nature of our results, we believe that our exercise serves well the purpose of posing the question of the need of alternative measures. Moreover, it is based on a relatively simple calculation, which makes the results easily intelligible, and on a clear explication of theoretical premises.

\subsection{Basic characteristics of an alternative estimation method}

We will refrain, in this paper, from a detailed exposition of our theoretical approach, for which we refer to Palumbo (2015, see esp. section 2). With respect to the mainstream view of the growth process, the demand-led growth perspective implies a reverse direction of causation as regards the relationship between growth of actual output and growth of potential output. The absence of neoclassical mechanisms supposedly ensuring full employment implies the possibility that the level of actual output may lie anywhere within the limits given by the productive possibilities. Thus, in each period a discrepancy may appear between actual and potential output. The latter, however, evolves over time on the basis of actual realizations, since unused resources tend to slowly shrink and disappear, while, conversely, the pace of resource creation may be accelerated under the pressure of high demand. It is thus actual output that influences, over time, the growth of capacity, labor force and productivity, rather than the other way round.

This theoretical perspective, together with the review of the defects of the standard estimation methods, allow us to define the basic desirable characteristics of an alternative measure of potential output.

In the first place, given that much critical literature has shown the non-existence of theoretical mechanisms ensuring the tendency to equilibrium in the labor market, and the above-described failure in the empirical identification of the NAIRU, we believe that a sound measure of potential output must entirely refrain from referring to that notion. Relatedly, inflation data should not be used in the estimation procedure, because 
the absence of any stable relationship in the data between output changes and inflation changes points to the need of a far more complex analysis of the determinants of inflation than the one implicit in the various versions of the Phillips curve. ${ }^{25}$ The presence of diverse autonomous factors affecting inflation can help explain the relevant changes in shape and position that estimated Phillips curves show across different countries and different periods. ${ }^{26}$ Deferring a deeper analysis of this issue to future work, we think that declining to use inflation data in estimating potential output is an acceptable first approximation. ${ }^{27}$

In the second place, the estimation method should not contain any a priori definition of potential output as the average trend of actual output. Rather, potential output should in our view be measured as a target magnitude, i.e. as the output that could be obtained, in any given situation, by fully (or normally) using the available resources, thus allowing for actual output to considerably deviate from it in case of deep recessions. It should be defined, in other words, as a full-employment ceiling, a target that the economy reaches only when aggregate demand is strong enough.

Looking back at the early literature on the empirical definition and estimation of potential output, one may note that the method originally proposed by Arthur M. Okun in the 1960s and used by the Council of Economic Advisers to estimate the potential GNP of the USA, although not immune from arbitrary assumptions, shares in some degree these two desirable characteristics. We thus propose in this paper a modern reformulation of Okun's original method, starting from an analysis of his theoretical premises and assumptions. ${ }^{28}$

\subsection{Okun's definition of potential output}

Okun (1962, p.1) proposed his method to estimate potential output as a way to address the question "how much output can the economy produce under conditions of

25 See for example Serrano (2006), who suggests that, according to the demand-led growth approach, aggregate demand shocks should not be regarded as giving rise to persistent inflation, given the long-run adaptability of resources to demand changes; while the causes of persistent inflation should be looked for in supply factors, according to the cost-push inflation tradition. See also Stirati (2001), for an analysis of the relationship between distributive conflict and inflation.

${ }^{26}$ As regards in particular the determination of money wages (which in all kinds of Phillips-curve models are considered as the main or sole source of persistent inflation), much of the pre-Phillips literature highlighted the role of institutional factors, social norms and the distributive conflict, thus eschewing the idea of a single clear-cut relation between unemployment (or activity) and wages (or their velocity of change). See Forder (2014) for a reconstruction.

27 Obviously, the non-existence of a univocal Phillips-type relationship does not imply the absence of any effects of employment (and unemployment) on wages and prices, but rather to need to address inflation concerns by means of dedicated policies rather than by curbing the level of activity. See below, section 6 , for some hints on policy implications.

${ }^{28}$ As will be made clearer in the following, since our analysis intends to recover the basic characteristics of Okun's original method and essentially re-propose his procedure, it is very different from the use that some of the current literature makes of parts of Okun's analysis in potential output estimation. Some authors (for example Apel and Jansson 1999a; 1999b; Lee 2000; Fabiani and Mestre 2004) estimate potential output using Okun's Law together with the Phillips curve, thus replacing Okun's 'target' rate of unemployment with the NAIRU, which in turn is estimated through the techniques described in section 1. For a fuller discussion of other possible uses and interpretations of Okun's Law, different from ours, see section 3 below. 
full employment." His theoretical reference was thus clearly Keynes's economics, and his measure was strictly functional to the full-employment policies that were pursued by the US administration in those years. ${ }^{29}$ The attainment of full employment required, in this view, output expansion through fiscal and monetary policies, and this was the rationale for translating the employment target into an output measure.

Thus Okun's potential output is definitely a target measure. He explicitly refuses to consider deviations from peaks as a sufficient measure of underutilization of labor and production possibilities, given that historical peaks may themselves be characterized by underutilization (see 1962, p. 1). His method consists, as a first step, in identifying a 'target' rate of unemployment, and, as a second step, in establishing a relationship between deviations of actual unemployment from its target value (the unemployment gaps) and percentage deviations of actual output from its potential, unobservable, level (the output gaps). This is derived from the empirical relationship between unemployment changes and output changes known in the literature as "Okun's Law".

\subsubsection{The assumptions. Potential output as a 'short-run concept'}

This procedure, as Okun (1962) himself makes clear, is based on the following assumptions:

i) empirical evidence bears out a fairly stable relationship between changes in unemployment and changes in output;

ii) the unemployment rate is a reliable indicator of labor underutilization and allows to gauge correctly the underutilization of capacity.

These two hypotheses are regarded by Okun as an acceptable first approximation, but he also offers interesting observations on both, which are at the basis of some of the modifications we will propose below to Okun's original method.

As regards hypothesis i), Okun (1962) extracts from quarterly data on the 19471960 period the well-known 3:1 relation between output gaps and unemployment gaps (Okun's Law). This is obtained by means of three different methods: the "first differences" method, which relates actual changes in unemployment to actual rates of growth of real output; the "trial gap" method, in which different exponential trends are hypothesized and then the actual unemployment rate is related to the resulting different series of output gaps in search of the best fit; and the method of "fitted trend and elasticity," based on the assumption of a constant elasticity relationship between the actual/potential output ratio and the actual/potential labor employment ratio and a constant-rate growth of potential output. In Okun's original analysis the three methods give very similar results; in our own estimates we will make use only of the first one, which does not require any pre-definition of trend nor additional hypotheses for the extraction of the statistical relationship. A more detailed discussion of methods is

29 The Employment Act of 1946 committed the Federal Government to the active pursuit of a target of "maximum employment", although, according to DeLong (1996), this policy was only partly implemented in subsequent years and with different intensity in different periods. The early 1960s may however be characterized as a period in which full employment was a priority policy target. 
however contained in sections 3 and 4 below.

Although data bore out a quite reliable 3:1 relationship, Okun (1962, p. 3) was cautious about its practical applicability. He noted in fact: "[i]n the periods from which this relationship was obtained the unemployment rate varied from about 3 to $7 \frac{1}{2}$ percent; the relation is not meant to be extrapolated outside this range." He thus expects that higher (or, for that matter, lower) levels of unemployment may return a different coefficient. In addition, since the obtained series of potential output "is a curve that wiggles from quarter to quarter, even dipping at times," he suspects that this "should be attributed to an imperfect correlation of the unemployment rate with unused potential output" (ibidem).

As regards hypothesis ii), it should be noted that the procedure does not require any hypothesis of strict constancy of labor productivity and the rate of participation to the labor force - quite the contrary. Okun (1962, p. 2) believes that a low level of unemployment would induce higher participation, while productivity would be affected by "added workers, changed average hours, possible alterations in the sectoral distribution of employment, higher utilization rate of capital, and altered efficiency in the use of employees." $30 \mathrm{He}$ assumes however that such changes are correlated with changes in the unemployment rate ${ }^{31}$ and notes that, if labor productivity and the labor force were constant, the relation between output gaps and unemployment gaps would be approximately $1: 1$, contrary to evidence. ${ }^{32}$ Such changes in productivity and labor force may be regarded as short-run variations due to the varying intensity of input utilization.

Changes in the size of productive capacity and the increases in labor productivity brought about by technological progress, which become relevant when a long-period perspective is taken, are another matter. Okun's definition of potential output and his procedure for calculating it exclude these by definition. Accordingly, he qualifies his own notion of potential output as a "short-run concept," which aims to measure the amount of output that could have been produced in each period had all installed capacity been used fully, thus allowing for the full utilization of the labor force. In other words, it is calculated by taking as given (and equal to the actual ones), in each period, both installed capacity, and the state of technology (Okun 1962, p.1-2). He is quite

${ }^{30}$ A further reason why changes in unemployment affect productivity is analyzed in a subsequent article (Okun, 1973, p. 208): "I now believe that an important part of the process involves a downgrading of labor in a slack economy-high-quality workers avoiding unemployment by accepting low-quality and less productive jobs."

31 "[W]hatever the influence of slack economic activity on average hours, labor force participation, and manhour productivity, the magnitudes of all these effects are related to the unemployment rate. With this assumption, the unemployment rate can be viewed as a proxy variable for all the ways in which output is affected by idle resources. The measurement of potential output then is simplified into an estimate of how much output is depressed by unemployment in excess of four percent" (Okun 1962, p.2). In a later article Okun (1973) reviews the literature trying to quantify these effects, providing also some detailed calculations of them separately, and concludes that the 3:1 relationship is largely confirmed (see especially pp.209-214).

32 A one-percentage-point change in unemployment entails in fact a change in employment slightly above 1 percent (1.05 percent if unemployment is initially 5 percent; 1.11 if initial unemployment is 10 percent). 
explicit on the possible effects of the level of activity on these supply factors, which he sees as relevant as soon as a longer-period perspective is taken, ${ }^{33}$ but does not consider such effects in his proposed measure of potential output, given its intended use as a tool for short-period policy.

\subsubsection{The target rate of unemployment}

The determination of the target rate of unemployment is a crucial piece of Okun's methodology. Consistently with its target nature, it is fixed exogenously, at a politically chosen arbitrary level. The precise number is set by Okun at 4 percent, and reflects an unemployment level that at the time was considered greater than the measure of 'true' full employment (then regarded in the vicinity of 3 percent, see Bronfenbrenner and Holzman 1963; Schwarzer 2018) by a sufficient margin to check for excessive inflationary pressures. Another reason in favor of such a number is the fact that a 4 percent unemployment rate was actually observable at a point of time in the estimation interval considered by $\mathrm{Okun}^{34}$, which allowed him to reconstruct the series of potential output starting from a known output level. As a third reason, it may be surmised, 4 percent was regarded as an actually attainable unemployment rate, provided appropriate expansionary policies were adopted, thus representing a realistic policy objective. ${ }^{35}$

Okun's definition of potential output as a high-activity level implies that the resulting estimated output gaps are strongly asymmetrical and almost exclusively negative (see Okun 1962, p.4). The main difference with the various estimation methods reviewed in section 1 lies in the total absence of any notion of 'equilibrium' rate of unemployment and in the fact that inflation data do not play any role in the estimation procedure. Even if Okun regards the 4 percent unemployment rate as safe enough to keep inflationary pressures at bay, he does not necessarily maintain that a quantitatively precise relationship may be defined between unemployment and inflation, nor does he calculate the "non-inflationary" rate of unemployment on this basis, but insists on its nature of a high-activity policy target. ${ }^{36}$

33 Okun (1973, p. 213), also notes that the "productivity bonus from higher utilization" persists beyond the short run, which he finds theoretically puzzling given the law of diminishing returns. For a discussion of the long-run effects of low unemployment, see our own attempt to build a 'high-demand potential path' in section 5 below.

34 When Okun (1962) estimated potential output over the interval 1954-62, unemployment was recorded as slightly below 4 percent in mid-1955. According to the updated BLS data we use, unemployment in the third quarter of 1955 was 4.1 percent.

35 "Involuntary unemployment is the most dramatic sign and disheartening consequence of underutilization of productive capacity... We cannot afford to settle for any prescribed level of unemployment. But for working purposes we view a 4 percent unemployment rate as a temporary target... The achievable rate can be lowered still further by effective policies to help the labor force acquire the skills and mobility appropriate to a changing economy" (J.F. Kennedy, "Message to the Congress Presenting the President's Economic Report", January 20, 1962, in Public Papers of the Presidents of the United States: John F. Kennedy; Containing the Public Messages, Speeches, and Statements of the President, January 1 to December 31, 1962, published by United States Government Printing Office, 1963).

36 "Economists have never developed a clear criterion of tolerable price behavior or any quantitative balancing of conflicting objectives which could be invoked either to support or attack the target of a four percent rate. Indeed, I should expect that many economists who agree on the four percent target would disagree in estimating how prices and wages would behave if we were on target” (Okun, 1962, p.1). 
The arbitrary nature of the target also allows us to set different values for it. In the following, we will estimate potential output by assuming both a 4 percent and a different unemployment rate, which we derive as the historical minimum in the time series of actual unemployment in our sample.

\section{Okun's law: a survey}

Even if Okun's original method for potential output estimation has been abandoned and gradually replaced by the methods described in Section 1, the empirical literature on Okun's law has continued to flourish in the recent decades. Not only, in fact, is the output-unemployment relationship a possible ingredient in potential output estimation when his target unemployment rate is replaced by the NAIRU (see footnote 27 section 2.1 for references); but Okun's law is also studied independently of such estimation, for example to analyze the unemployment cost of falls in output.

\subsection{Methods and theoretical interpretations}

Only two of the three above-mentioned methods proposed by Okun (1962) are used in subsequent literature: the first difference method and the trial gap method, named in the literature as the 'difference specification' and the 'gap specification' respectively. The difference specification (see, among others, Lee 2000; Knotek 2007; Cazes and Verick 2011; Apap and Gravino 2014; Busetta and Corso 2011; Garavan 2017; Kargi 2014; Kreishan 2011; Akram et al., 2014; Sadiku et al. 2015; Micaleff 2016) consists in regressing the first differences of unemployment on the rate of growth of actual output:

$$
\Delta u_{t}=a+b g_{y, t}
$$

(estimated coefficient $b$ is labeled in the literature as the 'Okun coefficient'). The gap specification (Weber, 1995; Lal et al., 2010; Hussain e Raza, 2014; Knotek 2007; Moosa 2008; Ball et al. 2017; Micallef 2017; Freeman 2000; Apergis and Rezitis 2003; Villaverde and Maza, 2009; Lee 2000) derives the $b$ coefficient from the following equation:

$$
u_{t}-u_{t}^{p}=b\left(\frac{y_{t}^{p}-y_{t}}{y_{t}^{p}}\right)
$$

where the index $p$ refers to potential (either unemployment or output). ${ }^{37}$

Equation (1) is consistent with Okun's theoretical premise that changes in output determine changes in unemployment; moreover, estimation of coefficient $b$ is entirely

37 Okun's original definition of output gap was slightly different, being it expressed as a percentage of actual rather than potential output. The two formulations are however perfectly equivalent for practical purposes. 
based on observable magnitudes. The gap specification (equation 2) is instead based on two estimated magnitudes, potential output and potential unemployment, which are usually defined as trend magnitudes, and obtained either by applying statistical filters to the series of actual output and actual unemployment ${ }^{38}$ or by regressing the two variables on their time trends. ${ }^{39}$ Some authors (Apel and Jansson 1999a; 1999b; Lee 2000; Fabiani and Mestre 2004) define potential unemployment as the NAIRU and estimate it through the Kalman filter, also using inflation data. But by using the definition of potential unemployment as equilibrium unemployment rather than target unemployment, these gap specifications clearly differ from Okun's own method, in accordance with the change in underlying theory.

In some analyses, Okun's law is expressed with output on the left-hand side of the equation. The reciprocal of $b$ is obtained, in the difference specification, by regressing the rate of growth of output on unemployment changes (Lee, 2000; Busetta e Corso, 2008; Kreishan, 2011; Akram et al., 2014; Li and Mendieta-Muñoz 2018); and in the gap specification as the coefficient which links output gaps to unemployment gaps (Gordon 1984; Prachowny 1993; Abel and Bernanke 2005). According to Ball et al. (2017), this reflects a change in theoretical interpretation, whereby output, more in line with neoclassical theory, is seen as dependent on employment (and other factors of production) rather than the other way round. In this vein, some authors have amended the gap specification by suggesting that the relationship between output gaps and unemployment gaps has to derive from a full model of the economy. Gordon (1984) estimates the relation by decomposing output growth in its components and explicitly taking into account the effects of the growth of labor force, hours per employed person and productivity on the Okun coefficient; while Prachowny (1993) and Freeman (2001) derive the coefficient from modeling output growth through a dynamic version of an aggregate production function. In all these cases, estimation of the Okun coefficient requires additional theoretical hypotheses and is generally based on the pre-definition of potential output as trend output.

The gap specification may also be expressed in difference form, as shown by Abel and Bernanke (2005). To this end, some additional hypotheses are needed: that the potential rate of unemployment does not vary over time; that the actual/potential output ratio is close to unity; that the rate of growth of potential output is constant. Notice that in this case the constant term in the equation connecting the rate of growth of actual output to the first difference in unemployment would represent the constant rate of potential output growth (see also Ball et al. 2015, 2017). ${ }^{40}$

${ }^{38}$ Knotek (2007), Moosa (2008), Ball et al. (2017) and Micallef (2016) adopt the Hodrick-Prescott filter, while Freeman (2000) prefers the trend-cycle decomposition proposed by Baxter and King (1995). Apergis and Rezitis (2003) and Villaverde and Maza (2009) apply both.

39 See for example Weber (1995); Lal et al. (2010); Akram et al. (2014).

$4^{0} \mathrm{Li}$ and Mendieta-Muñoz (2018) use a difference specification in which output growth is regressed on the change in unemployment and interpret the constant term as the long-run rate of growth of potential output. This is derived, in their analysis, as "the rate of growth of output consistent with a constant unemployment rate", which would represent the growth in labor force and labor productivity and is 
The empirical literature on Okun's law has also added dynamic variants of both methods. In the dynamic variant of the difference specification, the difference in unemployment is regressed both on contemporary and on lagged output growth. Such model finds its rationale in the idea that firms may require some time to adjust employment, and individuals to enter or exit the labor force (Ball et al. 2017). It also squares with Okun's (1962, p. 5) observation that "unemployment in the current quarter depends on past as well as current levels of GNP, with a higher level of past output meaning less current unemployment." Most authors also add lagged observations of the dependent variable (i.e., an auto-regressive component; see Knotek 2007; Akram et al. 2014; Casez and Verick 2011; Sadiku et al. 2015; Micaleff 2016); while Gordon (1984), Moosa (2008) and Ball et al. (2017) estimate dynamic versions of the gap specification.

Although variously interpreted from the theoretical point of view, many of the above analyses offer in practice an estimate of the coefficient linking unemployment changes and output changes, and an assessment of the stability of such relation.

\subsection{Main results}

Though Okun's law finds overall confirmation, both on annual and quarterly data, the output-unemployment relationship seems to be quite variable across countries and some authors also find variability over time. Cross-country analyses (Lee 2000; Virén 2001; Mayes and Virén 2002; Sogner and Stiassny 2002; Stock and Vogler-Ludwig 2010; Cazes and Verick 2011; Ball et al. 2017; Perman and Tavera 2005; Garavan 2017; Moosa 1997; Malley and Moolana 2008; Paldam 1987; Freeman 2001) find very different coefficients for the different countries considered; which some attribute to the different rules and institutions of the different labor markets (the Okun coefficient is supposedly higher where the labor market is more flexible: see Moosa 1997; Lee 2000; Sogner and Stiassny 2002; Ball et al. 2017).

Some authors, like Busetta and Corso (2008, 2011), estimate Okun's law for Italy and find some intra-country variability at the regional level ${ }^{41}$; an analogous result is found by Villaverde and Maza (2009) for Spain. Busetta and Corso (2011) also advance the hypothesis that, in the case of Italy, other indicators of the labor market rather than the rate of unemployment are better correlated to output changes, leading to more robust results, compared to those obtained with the unemployment rate. Apap and Gravino (2014), using data for Malta, show a different reactivity of unemployment to sectoral output changes (manufacturing vs services).

As regards time variability of the Okun coefficient, Moosa (1997) applies the Chow

estimated through a time-varying parameter model that allows for time changes in potential growth. In a different theoretical context and with different hypotheses, we will similarly adopt a definition of long-run potential growth at constant unemployment in section 5 below.

${ }^{41}$ A similar result is obtained by Salvati (2015) by means of a Geographically Weighted Regression (GWR; see Fotheringam et al. 2002 for details on the method). 
test on data of the G-7 countries, finding evidence of a 1973 break; while Sogner and Stiassny (2002), by applying the same test to a sample of OECD countries, conclude there was a structural break in 1982-83 for many of the countries considered. By applying the Supremum Wald test, which identifies breaks of unknown date, Lee (2000) finds evidence of different break dates for different OECD countries and concludes there is evidence of structural instability in the Okun relationship.

The empirical literature on the USA is particularly rich and offers mixed results. Okun's law has been traditionally considered a stylized fact thanks to the regularity with which early empirical analyses found a stable relation between output growth and unemployment changes (see for example Hall and Taylor 1988). However, Gordon (1984) and Weber (1995) find evidence of structural breaks, while Knotek (2007), by using a rolling regression, detects a remarkable variability of the coefficient over the whole estimation period (1948-2007; US quarterly data). Meyer and Tasci (2012), through the same technique, find a similar result on the 1948-2011 period. ${ }^{42}$ In a recent scrutiny of the literature and re-estimation of the law, Ball et al. (2017), working with both quarterly and annual data on the period 1948-2013, conclude instead for a remarkable long-run stability of the Okun coefficient for the USA, estimating a constant 2:1 relationship for the whole 65-years period (they run the Supremum Wald test, finding no evidence of structural breaks). The relationship is more noisy when estimated on quarterly data.

Starting from Palley (1993), some authors have addressed the possible different reactivity of unemployment to output growth in expansionary and contractionary phases of the cycle (Lee 2000; Virén 2001; Mayes and Virén 2002; Busetta and Corso 2008; 2011; Cazes and Verick 2011; Garavan 2017; Micallef 2016). Using different techniques on different countries and periods, these studies seem on the whole to confirm a greater reactivity of unemployment in recessions. Notice that this asymmetry is detected also by Ball et al. (2017), who explain on this basis the less good fit of the law on quarterly data. In a recent article, Lim, Dixon and van Ours (2018) address the question by studying the relationship between changes in unemployment and labor flows on US quarterly data, 1990-2017. By focusing on the key role of lagged unemployment, they also find time stability of the Okun coefficient and asymmetry of the relationship in the different phases of the cycle. ${ }^{43}$

Lastly, it is worth noting that, differently from developed countries, attempts to estimate Okun's law in developing countries do generally find non-significant coefficients (see Moosa 2008 on a sample of North-African countries; Lal et al. 2010 and Akram et al. 2014 on Pakistan; Kreishan 2011 on Jordan; Sadiku et al. 2015 on the Republic of Macedonia).

$4^{2}$ The same technique is applied by Moosa (1997) and Cazes and Verick (2011) in cross-country analyses and Micallef (2016) on Malta; in all cases the Okun coefficient is not constant.

43 Labor flows are defined as changes of status between employment, unemployment and not in the labor force. The authors find a high correlation between net flows and lagged unemployment. 


\section{Calculation of potential output: Okun's method revisited}

\subsection{Estimate of Okun's Law}

In order to build our own estimate of potential output, in the first place we estimate the Okun coefficient. We test the difference specification of Okun's law (see section 3 for references) on US quarterly data over the period 1959Q4-2018Q3. ${ }^{44}$ As maintained above, the gap specification requires in fact additional arbitrary hypotheses and especially pre-defines potential output. We thus find it ill-suited to our purpose of deriving potential output from the estimated Okun coefficient. We choose to estimate the difference specification in its dynamic form, in order to capture the idea that firms may require some time to adjust employment, and individuals to enter or exit the labor force. Due to the presence of first-order autocorrelation in the data, we choose an ARMAX $(1,0)$ model, which models the dependent variable as an auto-regressive process AR(1) and in terms of a linear combination of exogenous variables. The appropriate number of lags for both dependent and independent variables have been checked through Akaike's information criteria.

We thus test the following ARMAX $(1,0)$ model with two lags of the independent variable:

$$
\Delta u_{t}=a+\gamma_{1} \Delta u_{t-1}+b_{1} g y_{t}+b_{2} g y_{t-1}+b_{3} g y_{t-2}+e_{t}
$$

where $\Delta u_{t}$ is the first difference in unemployment while $g y_{t}$ is the rate of growth of GDP. We have preliminarily run two stationary tests (Dickey-Fuller and Phillip-Perron) and found that stationarity is confirmed. Since the OLS regression shows not only serial autocorrelation but also heteroskedasticity, we take care of the latter through a robust variance estimation. Results are shown in table 1.

\footnotetext{
44 The data sources are the Bureau of Labor Statistics for the unemployment rate (Labor Force Statistics, seasonally adjusted rate of unemployment, 16 years and over) and the Bureau of Economic Analysis for gross domestic products (chained 2012 dollars, seasonally adjusted). All regressions are run by means of the STATA software.
} 


\section{Table 1. ARMAX model}

\begin{tabular}{|l|l|}
\hline Variables & Coefficients \\
\hline$g y_{t}$ & $-0.17^{* * *}$ \\
& $(0.0219)$ \\
\hline \multirow{2}{*}{$g y_{t-1}$} & $-0.13^{* * *}$ \\
& $(0.0228)$ \\
\hline$g y_{t-2}$ & $-0.07 * * *$ \\
$(0.0199)$
\end{tabular}

Significance levels: $* * * \mathrm{p}<0.01,{ }^{*} \mathrm{p}<0.05,{ }^{*} \mathrm{p}<0.1$

(Standard errors in brackets)

Our estimated equation for US quarterly data over the period 1959Q4-2018Q3 is therefore:

$$
\Delta u_{t}=0.27+0.41 \Delta u_{t-1}-0.17 g y_{t}-0.13 g y_{t-1}-0.07 g y_{t-2}
$$

Both the contemporaneous and the lagged values of output growth are significant in explaining unemployment changes; the cumulated effect is -0.37 , not far from Okun's original estimate.

Based on the literature (see section 3) and due to the length of the period we consider, we address the question of the possible variability of the Okun coefficient over time. ${ }^{45}$ In the first place, we test for the presence of a structural break through the Supremum Wald Test, ${ }^{46}$ which can detect a break of unknown date (Lee, 2000; Ball et al., 2017). The test detects a very significant break in 2009Q4 (see figure 1a) ${ }^{47}$; we thus test our model again by adding the following dummy variable:

break $=\left\{\begin{array}{l}1 \text { if } t \leq 2009 Q 4 \\ 0 \text { if } t>2009 Q 4\end{array}\right.$

Results are shown in table 2.

45 Volatility and non-normality of residuals also suggest that a better specification of the model is in order. See Appendix A1 for some diagnostic plots of residuals of this and the following models.

${ }^{46}$ The test has been run on the univariate OLS regression, i.e. with first difference in unemployment regressed only on contemporaneous output growth.

47 We ran the Supremum Wald test on the 1959-2009 sub-period, and on various other sub-periods, and found no other significant breaks. 


\section{Table 2. ARMAX model with structural break}

\begin{tabular}{|c|c|c|}
\hline Variables & Coefficients 1959Q4-2009Q4 & Coefficients 2010Q1-2018Q3 \\
\hline$g y_{t}$ & $\begin{array}{l}-0.26 * * * \\
(0.0786)\end{array}$ & $\begin{array}{l}0.07 \\
(0.0758)\end{array}$ \\
\hline$g y_{t-1}$ & $\begin{array}{l}-0.09 \\
(0.0737)\end{array}$ & $\begin{array}{l}-0.05 \\
(0.0709)\end{array}$ \\
\hline$g y_{t-2}$ & & $\begin{array}{l}-0.08 * * * \\
(0.0200)\end{array}$ \\
\hline Constant term & $\begin{array}{l}0.48 * * * \\
(0.0818)\end{array}$ & $\begin{array}{l}-0.14^{*} \\
(0.0768)\end{array}$ \\
\hline$\Delta u_{t-1}$ & $\begin{array}{l}0.25 * * * \\
(0.0793)\end{array}$ & \\
\hline$R^{2}$ & 0.68 & \\
\hline
\end{tabular}

Significance levels: $* * * \mathrm{p}<0.01, * * \mathrm{p}<0.05,{ }^{*} \mathrm{p}<0.1$

(Standard errors in brackets)

Non-significant interaction terms are dropped from the final estimate.

Figure 1

(a): plot of the observation-level Wald test statistics with respect to time;

(b): scatter plot with regression lines for the pre-break and post-break periods

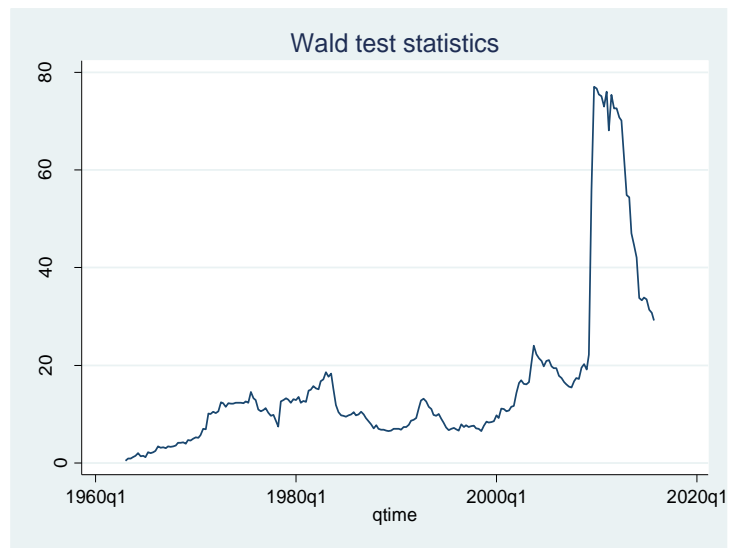

(a)

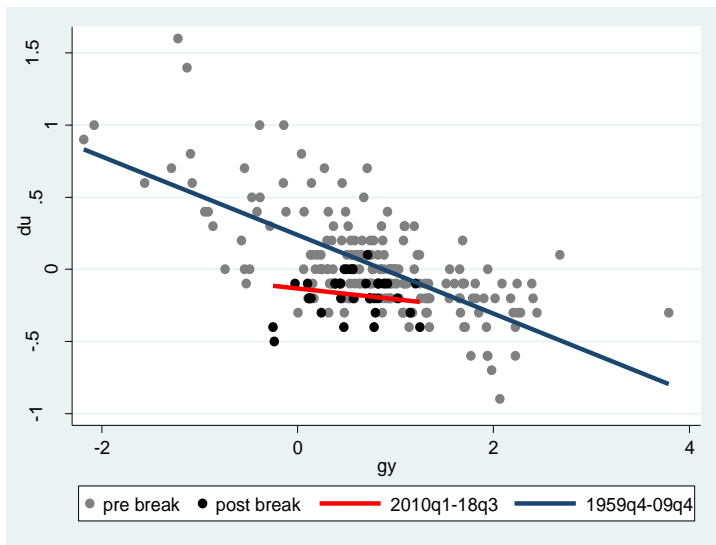

(b)

Our estimated equation is therefore:

$$
\Delta u_{t}=0.25 \Delta u_{t-1}-0.14-0.08 g y_{t-2}^{\text {post }}+0.48 \text { break }-0.26 g y_{t}^{\text {pre }}
$$

The fit of the regression improves. The estimated Okun coefficient is -0.26 in the prebreak period and -0.08 in the post-break period. The Okun relationship seems to change considerably in the post-2009 era, both in terms of the size of the coefficients and as regards timing: the effect of output growth on unemployment is in fact much lower with respect to the pre-break period, and only the influence of growth lagged over two periods is significant (only the contemporary effect is instead significant in the pre- 
break period). This would certainly call for a specific analysis of the post-2009 historical phase (see below, section 4.3, for some considerations).

Although the presence of the break improves our model we believe that a closer analysis is in order. In the first place, the Supremum Wald tests do actually detect some potential breaks in the pre-2009 period, albeit non-significant ones. In the second place, residuals seem to be particularly large and volatile, at least in some sub-periods of the pre-break phase (see figure A1.5 in Appendix A1) ${ }^{48}$. In the third place, as seen above, evidence in favor of a variable coefficient is produced in part of the literature; finally we suspect that over the long period considered there have been institutional changes that may have affected the output-unemployment relationship even before $2009 .{ }^{49}$ Following the suggestion in Knotek (2007), we thus perform a set of rolling regressions, by estimating equation (3) on shifting 52-quarter samples ${ }^{50}$. If the coefficient should result similar across the different regressions, we could conclude in favor of stability. Results are shown in figure 2 .

Figure 2

Results of rolling regressions (value of coefficient $b$ ). Dates on horizontal axis show the final quarter of each sample. Each point represents a 52-quarter sample.

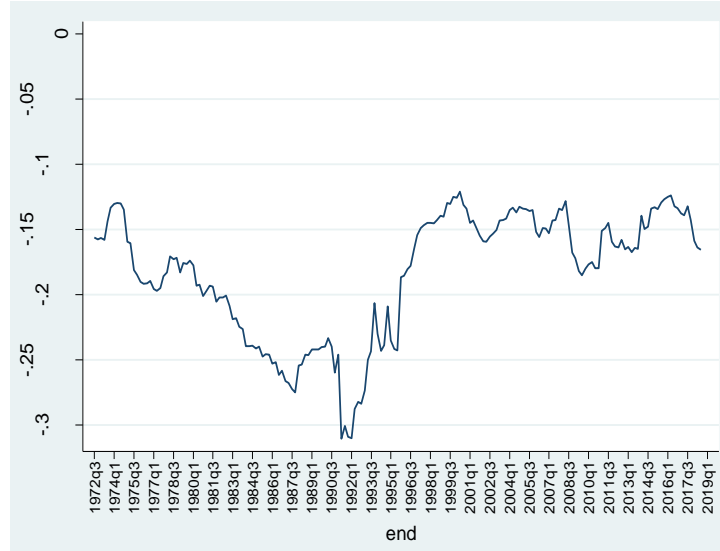

(a)

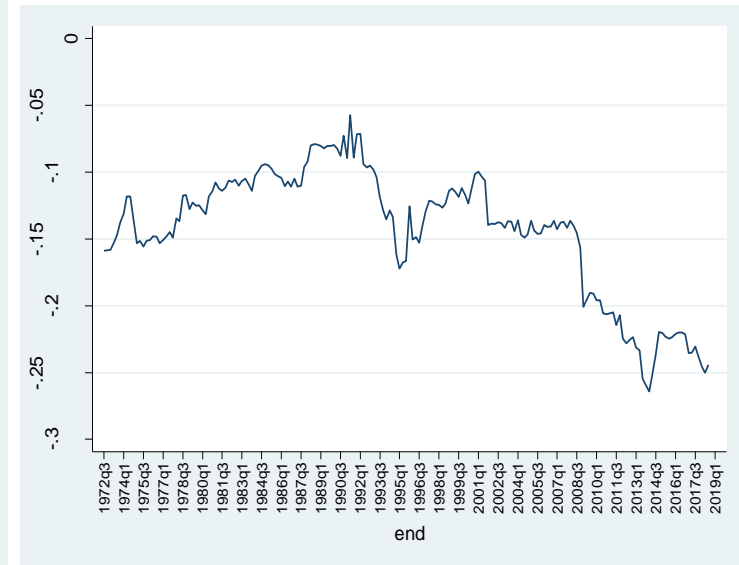

(b)

\footnotetext{
48 Figures A1.4 and A1.5 show a number of outliers, the most relevant of which is 1975Q1. The role of outliers in affecting coefficients will be investigated in our third model (see below, fn. 54).

49 "One problem with a long time series-such as from 1948 to 2007-is that history can hide changes in relationships" (Knotek 2007, p. 81).

$5^{\circ}$ For the length of the samples (52 quarters) we follow Knotek (2007). The rolling regressions technique implies that each sample starts and ends one quarter later than the previous one. See section 3 for references to other authors using the same technique.
} 


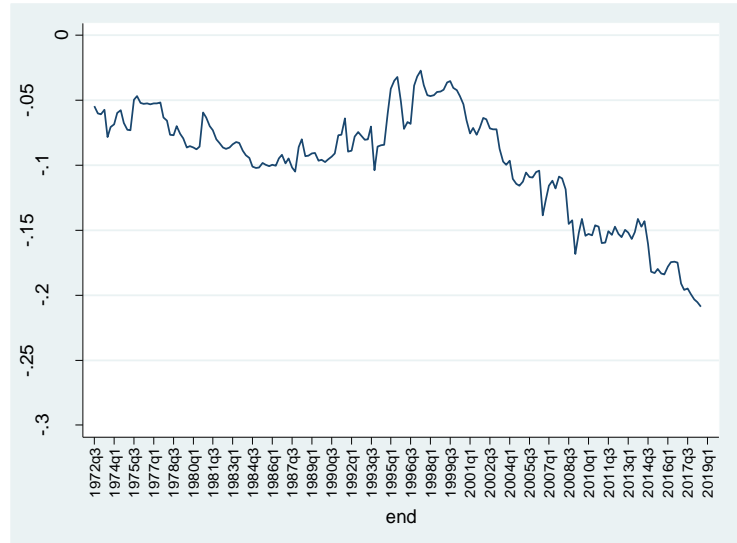

(c)

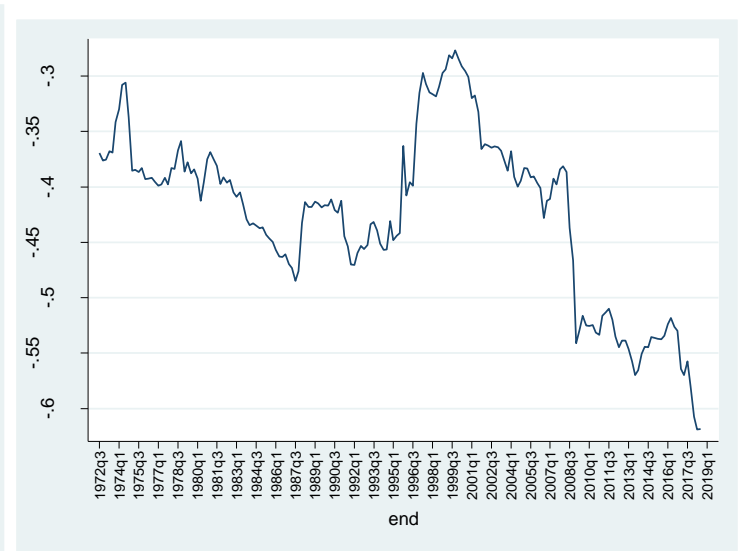

(d)

Diagrams (a), (b) and (c) represent respectively the effects on $\Delta u_{t}$ of the rate of output growth of period $t, t-1$ and $t$-2, while diagram (d) represents the cumulative effect. The Okun coefficient appears to vary considerably over the whole period; the latest periods including the 2009 crisis stand out for the particular high values (in absolute terms) of the cumulative coefficient. ${ }^{51}$ Our estimates thus reproduce the results noted in some of the literature: although the absence of statistically significant breaks in the 1959-2009 period allows us to conclude for the stability of the relationship in a period of fifty years, on closer examination the coefficient seems quite variable even in that period. Deep recessions, moreover, seem to have the effect of increasing the reactivity of unemployment changes to output growth. ${ }^{52}$

As noted above, the literature has advanced the hypothesis of a possible asymmetric response of unemployment to changes in the rate of growth of output in the different phases of the cycle (see section 3 for references). As an original contribution of this paper, we choose to test here a different hypothesis, namely that the reactivity of unemployment to output growth is different according to the level of the rate of unemployment. The intuition, also based on an observation by Okun $(1962)^{53}$, is that firms may be cautious in firing workers when the level of activity is below full, but may accelerate dismissals in case of deep slack. Considering changes in the opposite direction, recovery from a deep recession with high unemployment rates may imply faster re-absorption of potential workers (supposedly abundant and cheap), while when unemployment decreases below a certain level its reactivity to output growth will likely decrease. $^{54}$

\footnotetext{
${ }^{1}$ The length of the rolling samples (52 quarters) implies that all the end-dates in graph (d) from 2010 to 2018q3 include the Great Recession.

$5^{2}$ The observation is reinforced when considering that 1975Q1 (which is an outlier due to the big reaction of $\Delta u$ to output growth, see above) may also be characterized as a deep recession, being a third consecutive quarter of negative growth (the only case in the whole sample along with 2009Q1).

53 "I have no reason to expect the 3.2 coefficient to apply if unemployment were either 1 or 15 percent of the labor force" (Okun 1962, p. 3; see also above, section 2.2.1).

54 Such a hypothesis also implies that we are assuming, in parallel, different short-term effects of output growth on productivity according to the level of unemployment (lower effects at high unemployment and higher effects at low unemployment). Our hypothesis is based on an intuition in Okun (1973).
} 
To test this hypothesis, we define three different ranges of the unemployment rate, respectively labeled low (L), medium $(\mathrm{M})$ and high $(\mathrm{H})$ unemployment. The limit values of the ranges have been identified arbitrarily, on the criterion that each of the three ranges contains about a third of the observed values:

- $u_{L O W}\left(u_{t} \leq 5.2\right)$

- $u_{\text {MEDIUM }}\left(5.3 \leq u_{t} \leq 6.6\right)$

- $u_{H I G H}\left(u_{t} \geq 6.7\right)$

We thus insert three dummies in our model, which are defined as follows:

$$
\begin{aligned}
& L=\left\{\begin{array}{lr}
1 & \text { if } u_{t} \leq 5.2 \\
0 & \text { otherwise }
\end{array}\right. \\
& M= \begin{cases}1 & \text { if } 5.3 \leq u \leq 6.6 \\
0 & \text { otherwise }\end{cases} \\
& H= \begin{cases}1 & \text { if } u \geq 6.7 \\
0 & \text { otherwise }\end{cases}
\end{aligned}
$$

In order to take care of the 2009Q4 structural break, we include the break dummy variable (defined as before, model 2). In this case, however, we do not consider its interaction effects. This choice has two justifications: in the first place, it allows us to keep the number of interaction effects within reasonable limits; in the second place, we suppose that the asymmetric response of unemployment to output growth at different levels of unemployment, if verified, could go some way towards explaining the particular behavior of the relationship in the post-2009 period. Results are shown in Table 3.

Table 3. ARMAX model with asymmetries depending on the level of unemployment

\begin{tabular}{|l|l|l|l|}
\hline & \multicolumn{1}{|c|}{$u_{\text {LOW }}$} & \multicolumn{1}{c|}{$u_{\text {MEDIUM }}$} & \multicolumn{1}{c|}{$u_{\text {HIGH }}$} \\
\hline \multirow{2}{*}{$g y_{t}$} & $-0.10^{* * *}$ & $-0.16^{* * *}$ & $-0.26^{* * *}$ \\
& $(0.0196)$ & $(0.0245)$ & $(0.0355)$ \\
\hline \multirow{2}{*}{$g y_{t-1}$} & $-0.10^{* * *}$ & $-0.14^{* * *}$ & $-0.14^{* * *}$ \\
& $(0.0243)$ & $(0.0380)$ & $(0.0326)$ \\
\hline \multirow{2}{*}{ Constant term } & $-0.09^{* * *}$ & $-0.09^{* * *}$ & $-0.09^{* *}$ \\
& $(0.0249)$ & $(0.0272)$ & $(0.0337)$ \\
\hline \multirow{2}{*}{ break } & $-0.15^{* *}$ & -0.07 & $0.11^{* *}$ \\
& $(0.0649)$ & $(0.0703)$ & $(0.0543)$ \\
\hline \multirow{2}{*}{$\Delta u_{t-1}$} & $0.28^{* * *}$ & & \\
\hline$R^{2}$ & $(0.0393)$ & & \\
\hline
\end{tabular}


Significance levels: $* * * p<0.01, * * p<0.05, * \mathrm{p}<0.1$

(Standard errors in brackets)

The resulting equation is:

$$
\begin{aligned}
& \Delta u_{t}=0.11-0.15 L+0.28 b r e a k+0.17 \Delta u_{t-1}-0.10 g y_{t}^{L}-0.16 g y_{t}^{M}-0.26 g y_{t}^{H}- \\
& 0.098 g y_{t-1}^{L}-0.14 g y_{t-1}^{M}-0.14 g y_{t-1}^{H}-0.09 g y_{t-2}^{L}-0.09 g y_{t-2}^{M}-0.09 g y_{t-2}^{H}
\end{aligned}
$$

Our hypothesis is confirmed: the three resulting Okun coefficients are remarkably different and all of them significant. Higher unemployment implies greater unemployment changes in response to output growth. The (cumulated) coefficients are the following:

$$
\begin{array}{ll}
u_{\text {LOW }}: & -0.29 \\
u_{\text {MEDIUM }}: & -0.39 \\
u_{\text {HIGH }}: & -0.49
\end{array}
$$

These results are at the basis of our estimation of potential output. The fit of the model is in fact reasonably good, although it manages only in part to reduce the volatility of residuals (see figure A1.8 in the Appendix), which however prove to be normally distributed (as shown by the Shapiro-Wilk test, see Appendix A1). Moreover, we checked the robustness of our results by experimenting with alternative models, all of which confirm the significance of the three ranges of unemployment and their ordering. ${ }^{55}$

\subsection{Estimates of potential output and the output gaps}

We thus use our estimated coefficients in order to calculate potential output. The equation is the following, which reproduces Okun's (1962) original equation, but allows for different coefficients for the different ranges of unemployment:

$$
\begin{array}{rrr}
y^{p}{ }_{t}=y_{t}\left[1+\beta_{H}\left(u_{t}-u^{*}\right)\right] & \text { if } u_{t} \geq 6.7 \\
y^{p}{ }_{t}=y_{t}\left[1+\beta_{M}\left(u_{t}-u^{*}\right)\right] & \text { if } 5.3 \leq u_{t} \leq 6.6 \\
y^{p}{ }_{t}=y_{t}\left[1+\beta_{L}\left(u_{t}-u^{*}\right)\right] & \text { if } u_{t} \leq 5.2
\end{array}
$$

\footnotetext{
55 In Appendix A2 we introduce an alternative definition of the three unemployment ranges (we label it the 'extreme ranges' hypothesis because there our 'low' and 'high' ranges contain only the extreme values of unemployment rates; see the appendix for details). With this alternative definition, there are some changes in the size of the coefficients but our qualitative results are entirely confirmed. In Appendix A3, we offer alternative estimates of our models (both with equal-size ranges, as in the text, and with the 'extreme' ranges defined in Appendix A2) in which dummies are introduced for the two most relevant and influential outliers (both individually and jointly). Even if there are some changes in the size of the coefficients, all our qualitative results are again fully confirmed.
} 
where $\beta=\frac{1}{b}$ is the reciprocal of the Okun coefficient and $u^{*}$ represents the target rate of unemployment. What we obtain and define as potential output is thus the level of output that should have been produced in each period, given the actual state of technology and installed capacity, in order to bring unemployment at its target level. As regards the latter, we calculate potential output by setting two different target unemployment rates: in the first place, following Okun, we set $u^{*}=4$ percent; ${ }^{56}$ in the second place we select the historical minimum rate of unemployment observed in the sample, thus setting $u^{*}=3.4$ percent. ${ }^{57}$. The two resulting series of potential output are shown and compared with the actual output series, respectively in figures 3 and 4 . For the sake of comparison with other methods, we label our own method as 'updated Okun method'.

Figure 3

Potential output (updated Okun method, UOM).

Target unemployment $=4$ percent

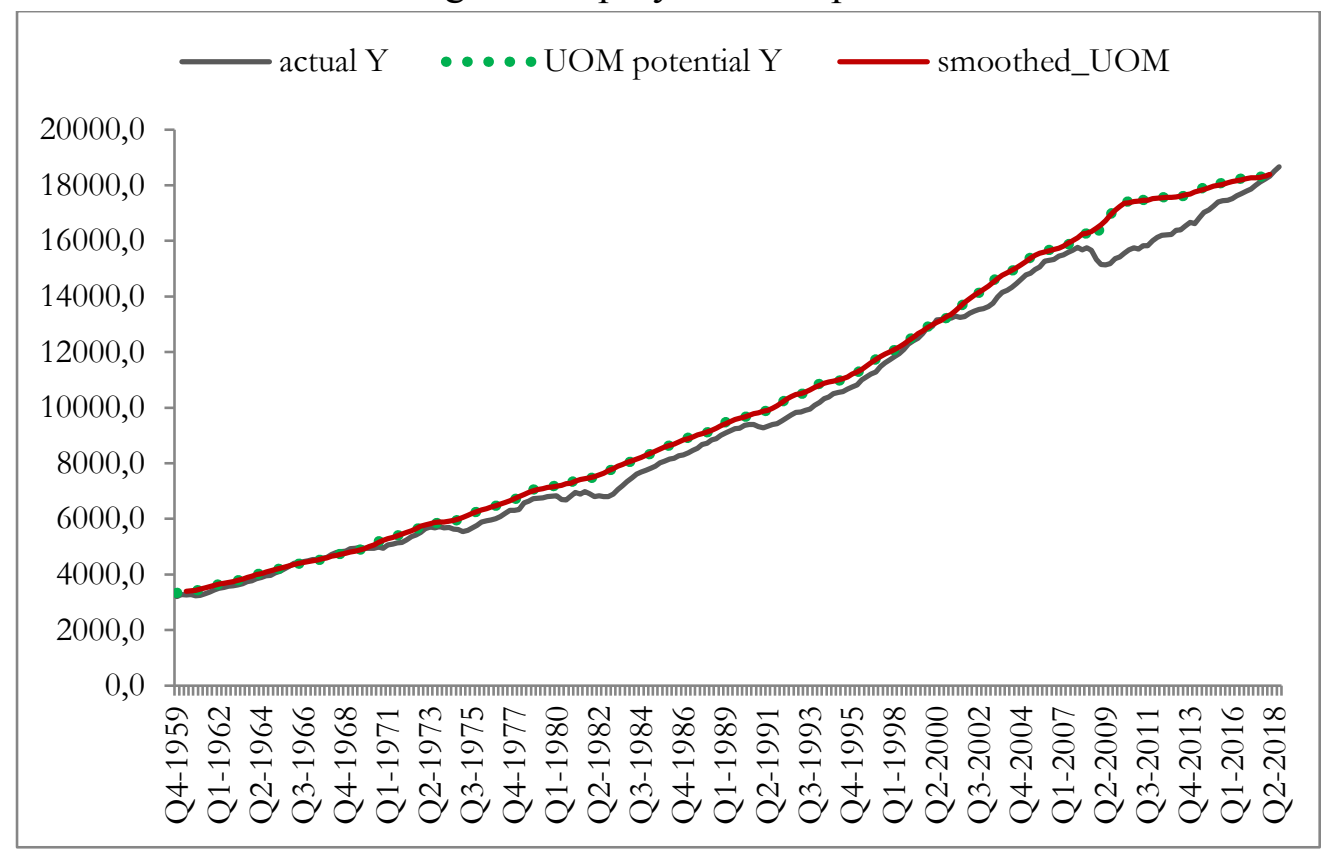

${ }^{56}$ In our sample, a rate of unemployment equal to or below 4 percent is observable in 22 quarters.

57 We select the minimum rate of unemployment measured as an average over any period of at least four consecutive quarters. The unemployment rate of 3.4 percent is the average over the 1968Q2-1969Q2 period. 
Figure 4

Potential output (updated Okun method, UOM).

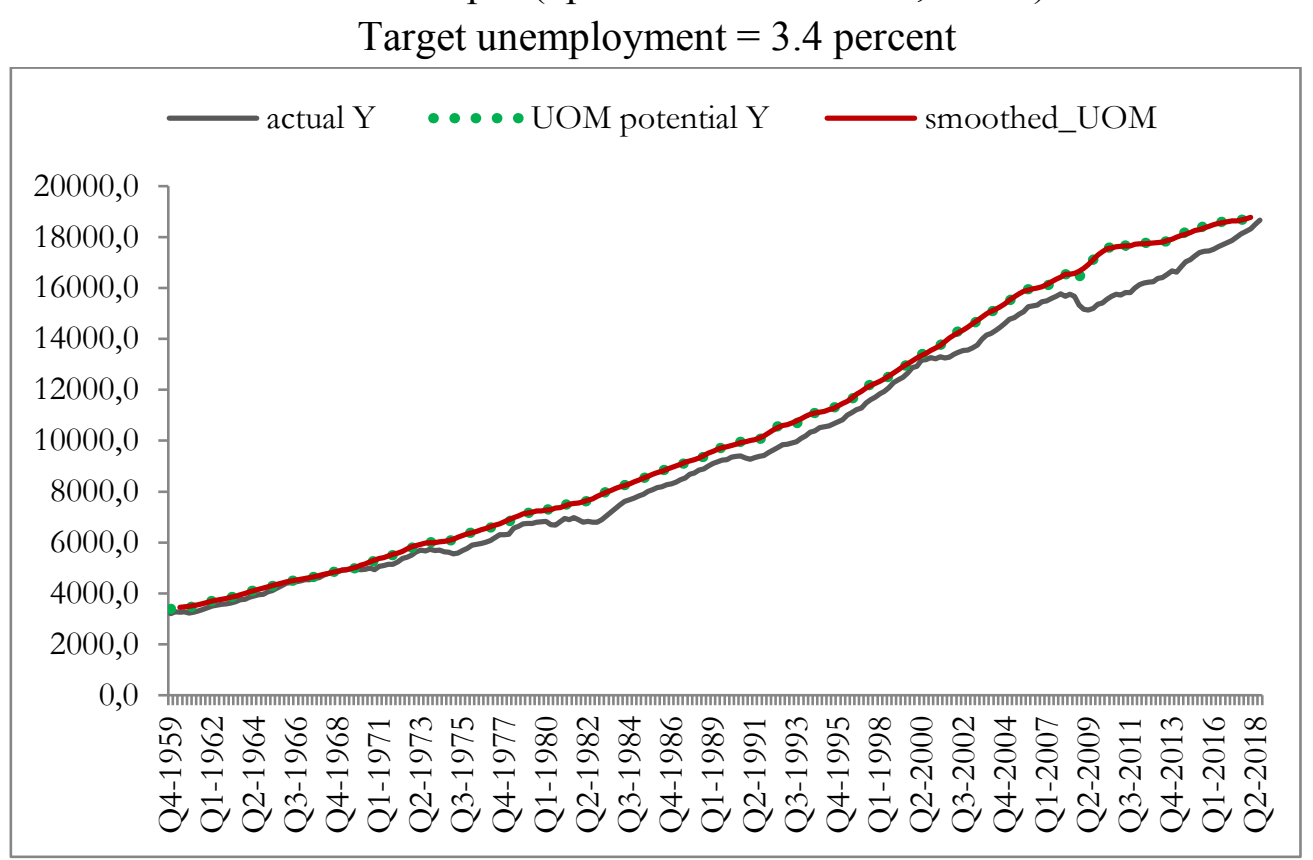

In both figures, the dotted line represents estimated potential output; the red line its 5 terms moving average, while the black line represents actual output.

The comparison between the output gaps that we obtain and the ones estimated by the $\mathrm{CBO}$ clearly shows the difference between the two estimation methods (figure 5).

Figure 5

Alternative measures of the output gaps

(our estimates compared to CBO's)

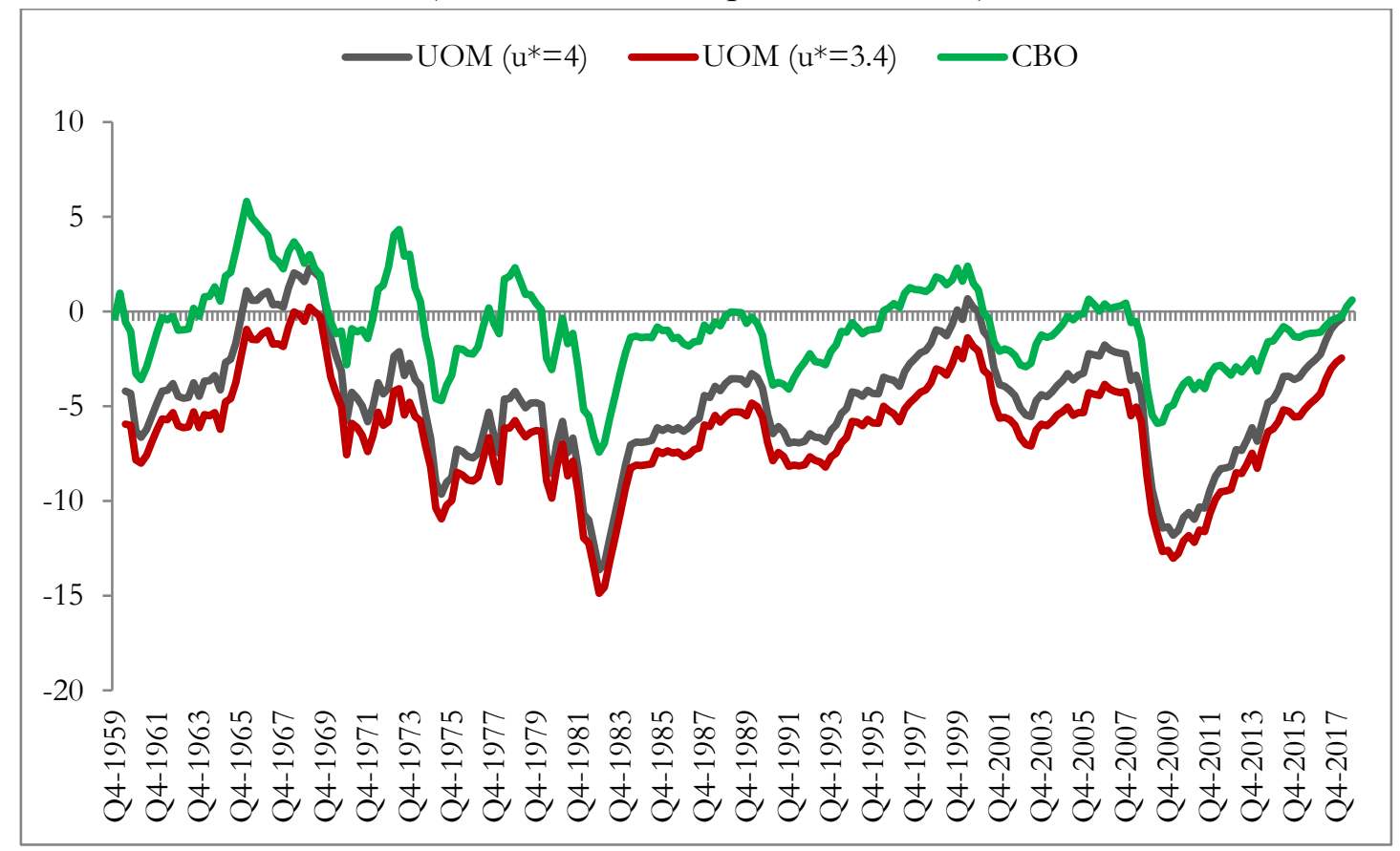


As is apparent, our 'updated Okun method' implies a very different definition and calculation of potential output with respect to the standard methods like the one used by the CBO. While the output gaps estimated by the $\mathrm{CBO}$ tend to fluctuate quite symmetrically around zero, our estimated output gaps are bigger in size and strongly asymmetrical (predominantly negative), the more so the lower the target rate of unemployment. This is consistent with our definition of potential output as an upper ceiling rather than the average trend of actual output.

\subsection{Significance and limits of our 'updated Okun method'}

Our proposed measure of potential output has some obvious limits, partly coming from the very assumptions on which it is based and partly because of the imperfect fit of Okun's law. In the first place, as noted above (section 2), Okun's procedure rests entirely on the idea that the rate of unemployment is a reliable indicator of labor and capacity underutilization: this might be questionable, especially in some particular historical phases, such as, for example, the one the American economy is experiencing in the 2010s. An already abundant literature advances the hypothesis that the current very low rates of unemployment in the USA do not imply that the economy is actually at full employment (or even beyond), but rather mask some relevant underutilization of labor. This would be reflected both in low participation rates and in short average working hours. ${ }^{58}$ The use of (official) unemployment data in our procedure would thus imply underestimation of potential output in the last part of the sample. ${ }^{59}$ A deeper analysis of this specific historical phase is certainly in order, which will be the object of future work. ${ }^{60}$

In the second place, it has been noted above that the correlation between unemployment changes and output growth, which holds on average over long periods, shows a certain volatility in the short period, which is captured only in part by our model "with asymmetries". In our opinion this implies that although our procedure is able in general to produce approximate assessments of the economy's potential, it should be used with extreme care for real-time estimates and predictions.

A further obvious limitation flows from our specific assumptions, for example the arbitrary definition of the three 'ranges' of unemployment rates (see however footnote 54 above, and Appendix A2). In all these respects, however, we deem our own estimation procedure and our results neither more arbitrary nor less reliable than the current standard ones. As noted in section 1 above, in fact, the latter are based not only

$5^{8}$ See for example Erceg, Levin 2013; Aaronson et al. 2014; Solow 2015; Summers 2017; Storm 2018; Cohen 2018.

59 The peculiar characteristics of the economy in the 2010s may explain not only the 2009 structural break, but also the less good fit of our models for that period (see above).

6o In the European context, a very recent contribution by Contini and Quaranta (2019) addresses the phenomenon of 'long-term non-employment', defined as the long-term incapability to access the labor market on the part of individuals that would like and would need to have a job after losing one. The empirical analysis that the authors conduct on Italy reveals that this kind of "premature and definitive labor market exit", if correctly computed as underutilization of potential labor, would imply revising heavily upwards the official unemployment rate. 
on questionable theoretical premises but also incorporate specific arbitrary assumptions about the equations and weighting parameters along with high volatility. At least the same caution that we advocate as regards the policy applicability of our estimates should be used with standard estimates.

For all its limits, we believe that our 'updated Okun method' for estimation of potential output has a distinct advantage with respect to standard estimation methods. Instead of defining potential output as the stochastic trend of actual output, thus assuming - but not proving - that the two can never diverge too much, our measure tries, though imperfectly, to identify and measure full-employment output, thus showing how far the economy may be from its target and how wide the margins are for output expansion in most circumstances.

Actually, the most relevant limit of our measure is the fact that it actually tends to underestimate systematically such margins. This is due, in part, to the choice of a positive non-negligible rate of unemployment as a measure for full employment (which rests on the assumption of the impracticality of aspiring to zero unemployment) and to the possibility that such an attainable measure could be further lowered by appropriate policies. ${ }^{61}$ A deeper reason, however, lies in the particular type of hypothetical reasoning on which our calculation is based. Estimation of potential output is in fact a counterfactual exercise: as noted in section 2 above, Okun's (and thus our) measure define a particular type of counterfactual, i.e. the level of output that would have been produced if, in any given situation, installed capacity were fully utilized. What this notion of potential does not consider are the possible effects of the actual level and growth of output on the future potential path of growth, thanks to the ways aggregate demand affects the very pace of capacity creation and may influence the velocity of adoption of technical innovations. It has been already noted, in fact, that for this reason Okun (1962) regards his own notion of potential output as a 'short-run concept'. Our next section attempts to surmount this restriction, by undertaking a different counterfactual exercise. We aim to estimate, albeit approximately, the long-period path of growth that the economy would have followed if aggregate demand had been persistently strong enough so as to produce unemployment rates always in the vicinity of the target and considering the effects of such high demand on the growth of productive forces.

\footnotetext{
${ }^{61}$ Even in the postwar period, when full employment policies reflected a serious commitment for many governments, the target was always a greater-than-zero unemployment. Beveridge (1944), for example, in his influent work, set it at 3 percent (for postwar Britain); while a report of the Department of Economic Affairs of the United Nations (National and International Measures for Full Employment) of 1949 recommended that each country fixed an unemployment percentage, or range of percentages, to be regarded as the full employment level. The frictions that prevent the economy from attaining zero unemployment were identified, at the time, with such phenomena as the possible discrepancy between the geographical distribution of jobs and the geographical distribution of the work force, the physiological voluntary mobility of workers between different jobs, and inter-sectoral shifts in the availability of jobs. It is worth noting that Beveridge (1944) regarded his own proposed 3 percent target as 'a conservative, rather than an unduly hopeful, aim to set' (p. 128), and believed that, by making use of appropriate supply policies, unemployment could be pushed below that level (pp. 198-201).
} 


\section{Measuring the high-demand potential path.}

In order to simulate such a hypothetical path of growth, we should model the longperiod effects of high aggregate demand on the growth of such supply factors as labor force, technical knowledge and the capital stock. ${ }^{62}$ In all probability, these effects are of different intensity in the different circumstances, and not easily represented by means of a simple general relation. Instead of trying to define such a general relation, our strategy thus consists in selecting, over the whole estimation period, those sub-periods in which the growth of demand was strongest, then projecting over the whole period the growth of supply factors that was actually observed in those sub-periods.

As a first step, we decompose output by means of the 'output identity' proposed by Gordon (2014):

$$
Y=\frac{Y}{H} \times \frac{H}{E} \times \frac{E}{L F} \times L F
$$

where $Y$ represents output, $H$ the total number of hours worked, $E$ employment and $L F$ the labor force. ${ }^{63}$ The same identity may be expressed in terms of rates of change:

$$
y=\pi+h+e+l f
$$

Equation (5) expresses the rate of growth of output as the sum of the rates of change of hourly labor productivity, hours worked per employed person, employment/labor force ratio $^{64}$ and labor force. As such, it is obviously an accounting identity, with no specific causal significance. According to our theoretical perspective, which emphasizes the role of demand in growth (see section 2.1 above), we assume that the causality runs from output growth to growth in employment, productivity, labor force and hours worked.

We thus observe the rates of growth of these magnitudes in our sample, by focusing exclusively on those sub-periods in which the rate of unemployment was below 5.3 percent (we maintain in the present exercise the same definition of 'low unemployment' that we proposed in our previous exercise in section 4). Table 4 shows the average rates of change of the components of output in such sub-periods. ${ }^{65}$

\footnotetext{
${ }^{62}$ See for example Fazzari et al. (2018) for an attempt in this direction.

63 It is worth noting that the decomposition proposed by Gordon (2014) includes a 'bridge term', given the different computation of hours worked in the magnitudes $H / E$ and $Y / H$. Such a correction is now unnecessary, being the alignment between the different sources already conducted by the Bureau of Labor Statistics in its data on total hours worked (see https://www.bls.gov/opub/hom/inp/calculation.htm\#hours-worked).

64 The employment/labor force ratio $E / L F$ is equal to $1-u$.

65 For the construction of Table 4 our inspiration is Gordon (2014, p. 7). His "benchmark quarters" are however identified on a different criterion (he chooses "cyclically neutral" quarters, that have roughly the same unemployment rates, which he regards as neither too high nor too low and thus supposedly pointing
} 
Table 4 - Percentage rates of change of output and its components in sub-periods in which $\mathrm{u}<5.3$ percent.

\begin{tabular}{|c|l|r|r|r|r|r|}
\hline \multicolumn{1}{|c|}{ Intervals } & \multicolumn{1}{c|}{ Length } & \multicolumn{1}{c|}{$y$} & \multicolumn{1}{c|}{$l f$} & \multicolumn{1}{c|}{$\pi$} & \multicolumn{1}{c|}{$h$} & \multicolumn{1}{c|}{$e$} \\
\hline 1964Q2-1970Q3 & 26 quarters & 1,00 & 0,50 & 0,59 & $-0,10$ & 0,00 \\
\hline 1973Q1-1974Q2 & 6 quarters & 0,17 & 0,75 & $-0,15$ & $-0,38$ & $-0,04$ \\
\hline 1997Q1-2001Q3 & 19 quarters & 0,89 & 0,32 & 0,64 & $-0,09$ & 0,02 \\
\hline 2005Q2-2008Q1 & 12 quarters & 0,50 & 0,28 & 0,25 & $-0,05$ & 0,01 \\
\hline 2015Q3-2018Q3 & 13 quarters & 0,57 & 0,26 & 0,14 & 0,05 & 0,12 \\
\hline
\end{tabular}

As is apparent, the growth of activity was not strong in all the periods characterized by low unemployment. In order to identify the 'phases of high demand' we are looking for, we thus require that two conditions are satisfied: i) the unemployment rate is below 5.3 percent; and ii) the rate of output growth is not lower than the average growth recorded in the entire sample (the latter being 0.75 percent per quarter). The two subperiods that satisfy these conditions are 1964Q2-1970Q3 and 1997Q1-2001Q3, which we consequently regard as our benchmark periods (highlighted in grey in the table). As an additional condition, it would be sensible to consider only periods that are long enough to allow assessment of the medium-to-long term impact of high demand on supply factors; however this condition is already satisfied by the two benchmark periods selected.

Our exercise consists in projecting over the whole 1959Q4-2018Q3 period the growth of labor force, productivity and hours per employed person recorded in the two benchmark periods, while assuming no change in the employment/labor force ratio $\left(e^{*}=0\right)$. This latter condition simulates an economy that is persistently kept at high levels of activity, so as to show, supposedly, no changes in unemployment away from the target. We thus focus on the other three factors that we define jointly, for the sake of simplicity, as "supply factors". ${ }^{6}$

To perform the simulation, we refer to the quarterly average rates of growth of the three 'supply factors' in the benchmark periods. These are shown again in Table 5.

to a "normal rate of utilization"). Both for this different criterion and because of the theoretical perspective we adopt, the use we make of the output identity is very different from Gordon's.

66 As noticed in section 3 above, a similar definition of the long-run rate of growth of potential output is to be found in Li and Mendieta-Muñoz (2018), who also identify it with the rate of growth of the labor input and labor productivity in the hypothesis of no change in unemployment. Their procedure for estimation of such a potential rate is however very different from ours, since they extract it as a trend from the series of actual output, thus finding a significant decline of such a rate in recent decades. 
Table 5 -Average quarterly rates of change -benchmark periods

\begin{tabular}{|l|l|c|c|c|c|c|c|}
\hline \multicolumn{2}{|c|}{} & $y$ & lf & $\pi$ & $h$ & $e$ & $y^{*}$ \\
\hline 1964Q2-1970Q3 & 26 quarters & $(1)$ & $(2)$ & $(3)$ & $(4)$ & $(5)$ & $(6)$ \\
\hline 1997Q1-2001Q3 & 19 quarters & 0,89 & 0,32 & 0,64 & $-0,09$ & 0,02 & $\mathbf{0 , 8 7}$ \\
\hline
\end{tabular}

Column (6) of Table 5 shows the 'potential growth rates of supply factors', which we obtain as the sum of columns (2), (3) and (4), by assuming $e^{*}=0$. We then construct the potential growth path by projecting such potential growth rates of supply factors on the whole 59-year period. In order to do so, we use the potential rates of growth of column (6) to calculate the coefficients of the linear trends in each of the two benchmark sub-periods, then obtain the time coefficient of the potential path as a linear combination of these two coefficients ${ }^{67}$. The resulting coefficient is then applied to our sample, starting from an initial value that we choose as the potential output of 1959Q4 (the value that we have previously calculated by means of our updated Okun method, see section 4). Finally, we add a random component to the long-period trend, which we obtain as the residual of a simple OLS estimate of the time trend of actual output by means of a piecewise linear regression:

$$
Y=f\left(T_{i}\right)+\varepsilon
$$

where the break points we choose are the peaks defined for the US economy by the National Bureau of Economic Research (NBER). We then add the estimated residuals $\widehat{\varepsilon_{t}}$ to our simulated trend.

Summing up, our simulated 'high-demand potential path' derives its trend from the growth in supply factors recorded in the two 'high-demand' (benchmark) sub-periods, and its random component from the deviations of actual output from its own time trend. The idea is to simulate the growth of an economy that is persistently characterized by high demand growth, but to allow for random deviations from such a high trend of growth, which would supposedly be short-lived because it would be promptly corrected by appropriate policies.

The results of our simulation exercise are shown in figures 6 and 7.

67 The procedure we adopt allows us to avoid cumulating a single (average) rate of growth over the whole simulation period, which would imply the use of an exponential trend that over long periods does not reproduce correctly the typical trend of output (see Blanchard et al. 2015). In order to identify the coefficient of the linear trend, in each of the two benchmark periods we apply the rate of growth to a level of output in the initial date (respectively, 1964Q2 and 1997Q1), which we identify with the level, in those dates, of the Updated-Okun-Method potential output calculated in section 4. It is worth noting that this procedure again tends, if anything, to underestimate the coefficients of the linear trends. For the reasons already explained, in fact, the high-demand potential path we are constructing lies above the trend of UOM potential (see also below in this section). 
Figure 6

Simulated high-demand potential path (HDPP) compared to

Updated-Okun-method (UOM) potential output. Target: $u^{*}=4$

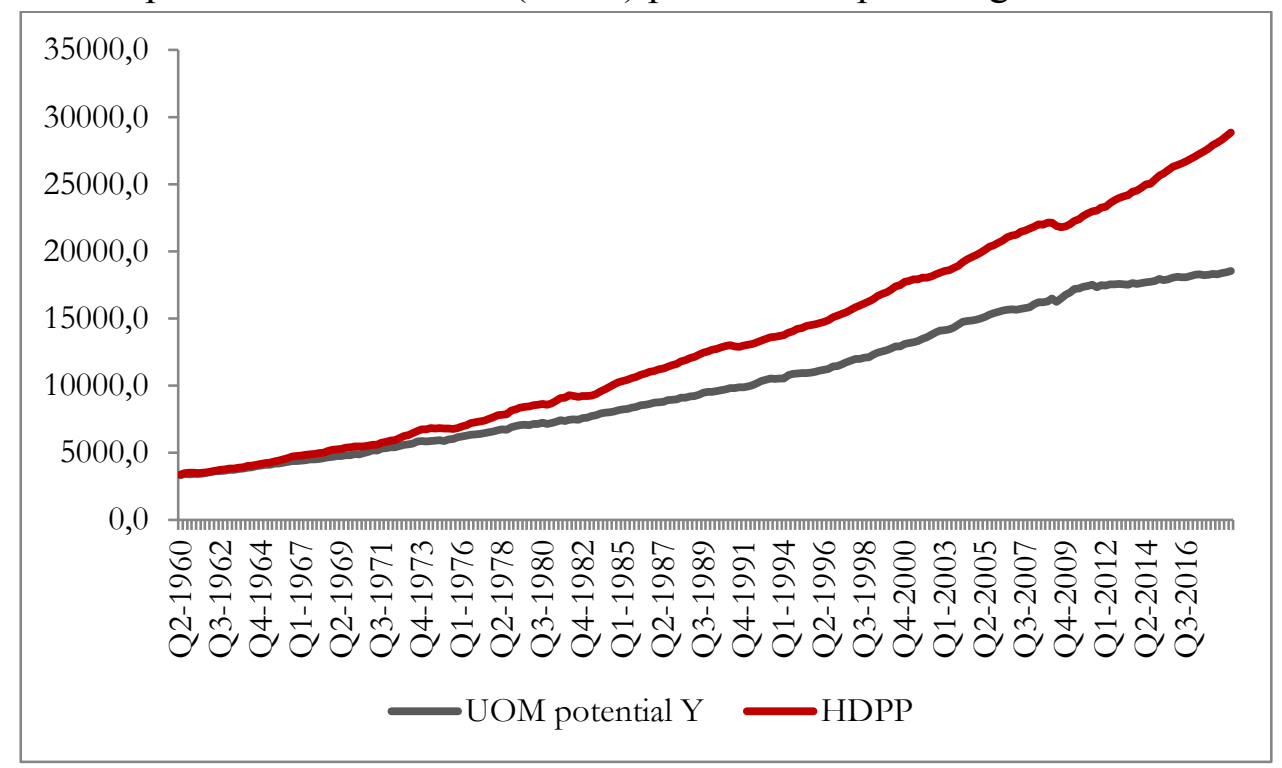

Figure 7

Simulated high-demand potential path (HDPP) compared to

Updated-Okun-method (UOM) potential output. Target: $u^{*}=3.4$

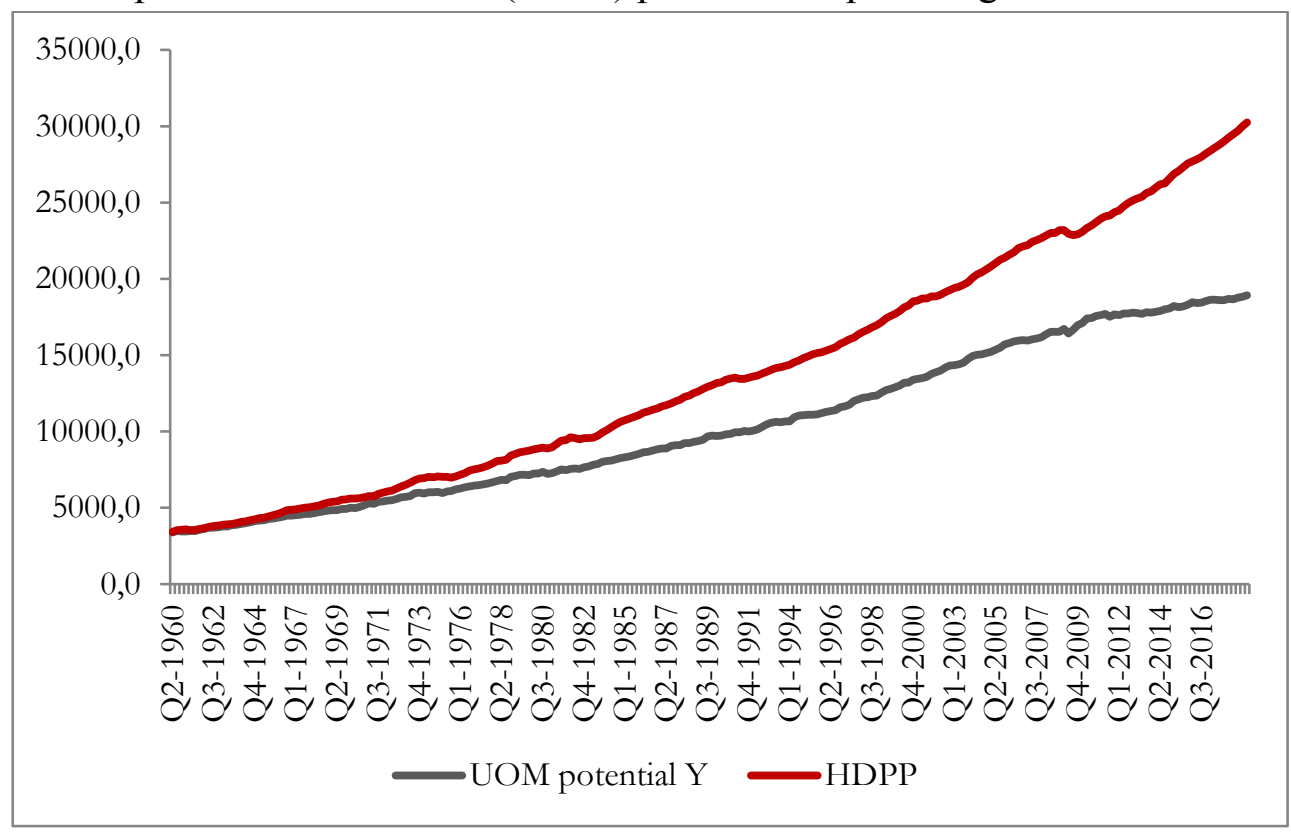

Notwithstanding the inevitable arbitrariness of the specific hypotheses and technical solutions we adopted, we believe that the comparison between the just-obtained highdemand potential path and the potential output measure that we have estimated in section 4 illustrates well the conceptual difference between the two different notions. While the Updated Okun Method simply aims to convert, in each given situation, the distance between actual unemployment and target unemployment in terms of output, the 
high-demand potential path simulates the path of growth that the economy would have followed had demand been maintained persistently strong. The difference between the two measures, that we define as the 'potential gap', is shown in Figure 8. Obviously, the fact that the potential gap is very low in the initial periods depends on the starting date of our simulation. As is implicit in the very definition of the high-demand potential path as a sort of maximum growth path, ${ }^{68}$ the gap tends to grow as the simulation period lengthens, since it accumulates the negative effects of all the downward deviations that have actually occurred from such a path.

Figure 8

Potential gap

Difference between HDPP and UOM-potential output

as a percentage of the former

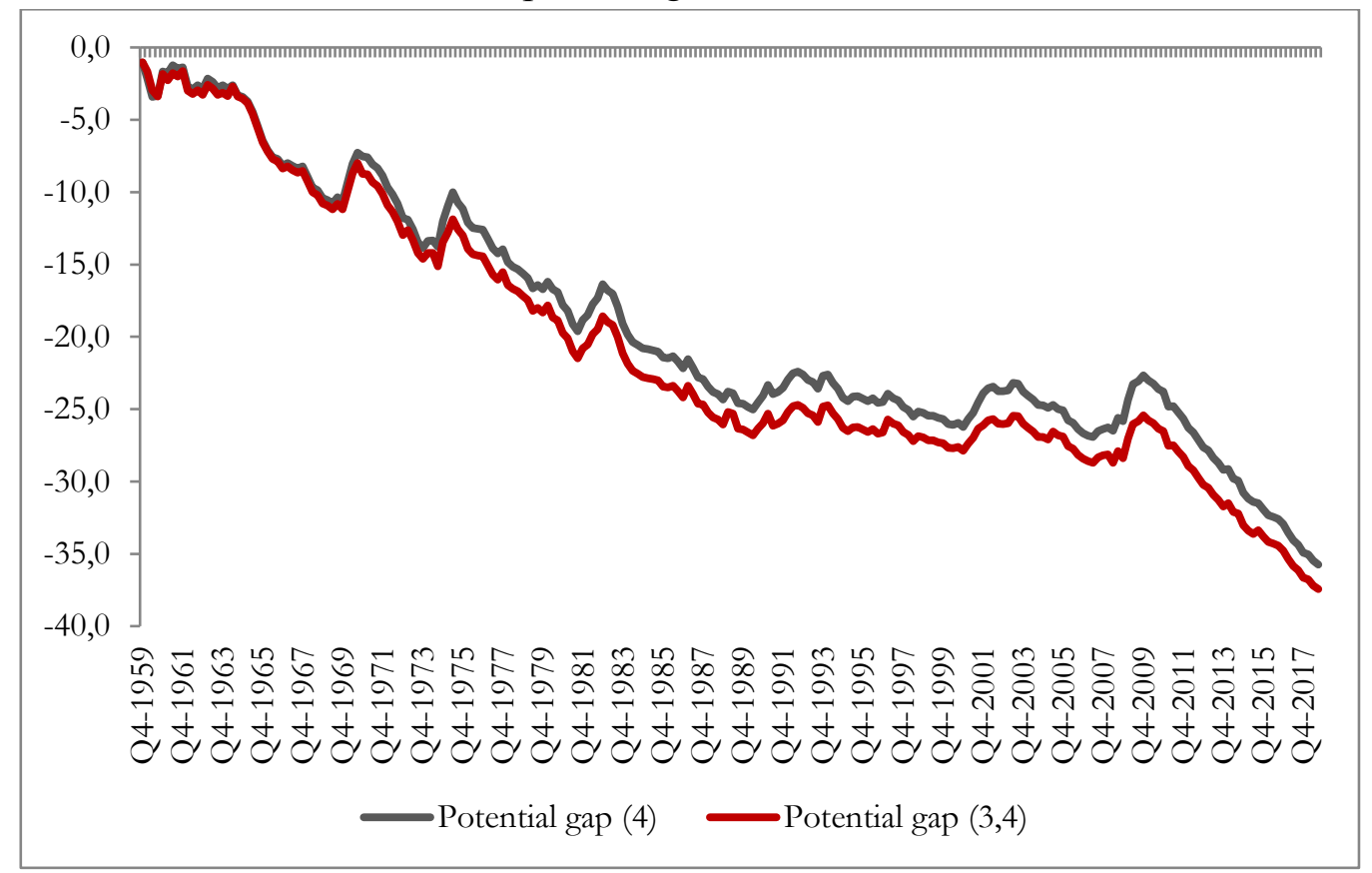

\section{Conclusions}

The two different measures of potential output we have obtained in sections 4 and 5 correspond to different conceptual notions and have different purposes. The updated Okun method aims to show in each period, given the growth of productive forces that has actually occurred, how far the economy was from a (conventional) full-employment target; the high-demand potential path, instead, shows at a certain date what the economy would have been able to produce if the growth of productive forces had been

\footnotetext{
68 Actually, the high-demand potential path is by no means characterized by the maximum rate of growth that the economy could have possibly attained, but by the maximum growth rate of supply factors observed historically as an average over a certain number of consecutive quarters (in our exercise, at least 19).
} 
fostered, over a long period in the past, by persistently strong demand. In figure 9 we reproduce the two series (for $u^{*}=3.4$ ), adding the time series of actual output. Although approximately, the comparison between the three series shows how far the sluggish growth of actual demand in some periods in the sample has prevented potential output (calculated through UOM) to grow as much as it could. We are aware of the arbitrariness of some of our hypotheses and are thus not claiming that our numbers offer a precise estimation of such a loss; however we believe that our exercise may at least give an idea of the possible order of magnitude of the phenomenon. According to our simulation, at 2018Q3 the distance between actual output and this wider notion of potential output was about 38 percent of the latter (or 62 percent of actual output).

Figure 9

A comparison between actual output, UOM potential output and the high-demand potential path $\left(\mathrm{u}^{*}=3.4\right)$

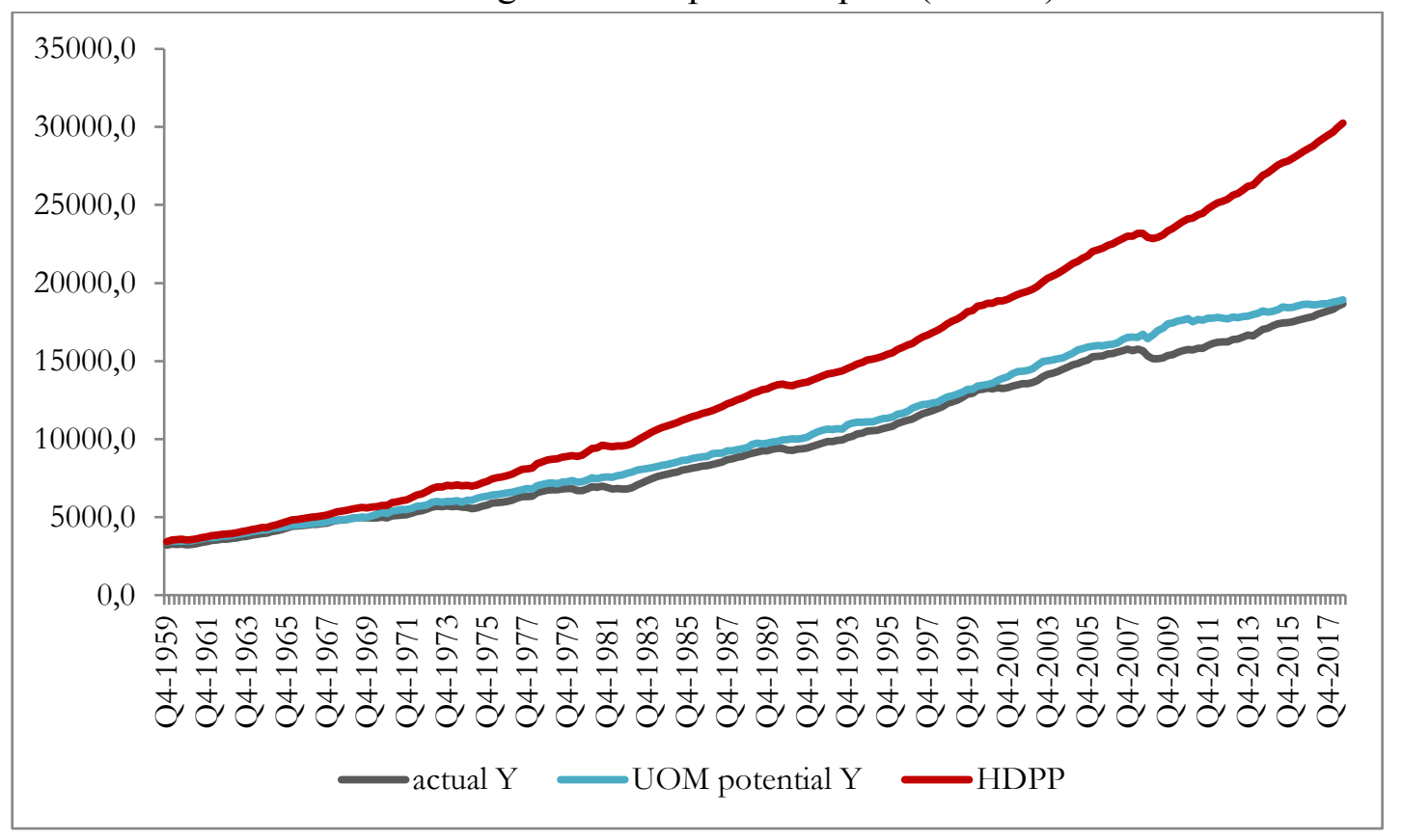

Going back to the question we posed in the beginning of this paper, we may thus conclude that the effects of the Great Recession have been both severe and long lasting. Not only do recessions open up big gaps between actual and potential output, but all phases of stagnating or slowly growing demand make the pace of resource accumulation and productivity growth slow down, thus causing a downward displacement of the whole long-run path of potential output.

The existence of such wide margins for potential output growth does not imply, of course, that they may be actually exploited entirely in a single period. But it implies that a determined policy of demand expansion would create, given time, the very capacity that justifies it. What kind of demand expansion would be more conducive to growth 
and what kind of supply policies should accompany it in order to avoid imbalances and prevent such undesirable side effects as inflation or foreign exchange shortage, are questions that cannot be addressed here. ${ }^{69}$ What we tried to show is that the flawed methods of estimation of potential output that are currently used by the main economic institutions, in addition to providing measures that systematically underestimate the margins for expansion of actual output, also divert attention from these more substantial policy issues. Alternative measures are possible, as we tried to show in this paper.

If no methods, ours included, are immune to arbitrary assumption and discretionary judgment, we cannot claim to have found the 'true' measures of the output gaps; yet we believe that our analysis may prove useful in at least a couple of different respects. In the first place, it shows how arbitrary the official measures of potential output and the output gaps are - thus adding to the warnings raised from various quarters against unconditioned faith in them. ${ }^{70}$ Although many experts and the same institutions that estimate output gaps are well aware of the limitations of the methods they use and the uncertain nature of their estimates, this does not prevent policies from being shaped on this basis - which more than once has implied forcing contractionary policies on already ailing economies, as happened with Southern European countries during the 2010s.

In the second place, our analysis shows why official measures of potential output (or possibly any measure of potential output), should not be mistaken for the threshold beyond which uncontrolled inflation explodes. With the CBO (2019, p.21) estimating that in the USA "real GDP began to exceed its potential level in early 2018", and "the growth of real GDP is expected to outpace the growth of its potential in 2019", so that "the output gap ... is expected to widen further this year", we should be witnessing by now an uncontrolled growth of wages and prices in the USA - which does not seem to be the case. In the early months of 2019, the American economy seems still able to create new jobs (although at a slower pace) and to produce some timid increase in labor force participation. As we tried to argue in section 2, the process of capacity creation induced by a sustained expansion of demand implies that potential output need not in general be defined as a limit that should be never crossed nor as the "inflation barrier", since the creation of additional resources stimulated by high demand may gradually remove the very bottlenecks that in the short period might produce inflation pressures.

What we especially tried to show is that the disappointing characteristics of standard estimates - in terms of volatility, unreliability, poor capability of predicting inflation,

\footnotetext{
69 With reference to the European context, Celi et al (2018), who offer a thorough and in-depth analysis of the productive and commercial disequilibria within the Eurozone in the context of the recent transformations in the international division of labor, conclude in favor of incisive industrial policies, especially aimed at reinforcing the productive bases of the Southern periphery of Europe. Expansion of aggregate demand, though strictly necessary, would not be sufficient in itself, according to their analysis, to guarantee long-term sustained growth in those economies.

${ }^{70}$ See Heimberger and Kapeller (2016) and the critical literature quoted in Section 1. A "Campaign Against Nonsense Output Gaps" has been recently launched on the social media by Robin Brooks of the Institute of International Finance and supported by authoritative scholars.
} 
need of repeated revisions - all have their roots in the very theoretical conception of potential output. The demand-led growth perspective allows a conceptual reconsideration and redefinition of it as a genuine measure of the economy's production possibilities, as is implicit in the very meaning of the word 'potential'. Just as an economy that has undergone deep recessions and long periods of slow growth has slowed down the pace of creation of its capacity or even destroyed part of it, thereby reducing its own growth prospects, so can it respond positively to a lasting expansion in demand and develop its capacities beyond the limits that now seem insurmountable. Potential output should somehow measure these possibilities, however far they are from what was realized, however complex it is to measure them with accuracy, however difficult may be to identify the proper set of policy measures that will make it possible to bridge the gap between what is and what could be.

\section{References}

Aaronson, S., Cajner, T., Fallick, B., Galbis-Reig, F., Smith, C., Wascher, W. (2014). Labor force participation: recent developments and future prospects. Brookings Papers on Economic Activity, 2014(2), 197-275.

Abel, A.B., Bernanke B.S. (2005), Macroeconomics, 5th edition, Pearson AddisonWesley: Boston.

Alichi, A., Bizimana, O., Laxton, M.D., Tanyeri, K., Wang, H., Yao, J., Zhang, F. (2017). Multivariate Filter Estimation of Potential Output for the United States. International Monetary Fund.

Anderton, R., Aranki, T., Dieppe, A., Elding, C., Haroutunian, S., Jacquinot, P., Szörfi, B. (2014). Potential output from a euro area perspective. European Central Bank. Occasional paper series, No 156.

Akram, M., Hussain, S., Raza, S. H., Masood, S. (2014). An empirical estimation of Okun's law in the Context of Pakistan. Journal of Finance and Economics, 2(5), 173177.

Apap, W., Gravino, D. (2014). Okun's Law in Malta: Lessons learnt from a sectoral perspective. Economic Policy Department Working Paper. Ministry for Finance: Malta.

Apel, M., Jansson, P. (1999a). System estimates of potential output and the NAIRU. Empirical Economics, 24(3), 373-388.

Apel, M., Jansson, P. (1999b). A theory-consistent system approach for estimating potential output and the NAIRU. Economics letters, 64(3), 271-275.

Apergis, N., Rezitis, A. (2003). An examination of Okun's law: evidence from regional areas in Greece. Applied Economics, 35(10), 1147-1151.

Ball, L. M. (2014). Long-term damage from the Great Recession in OECD countries, (No. w20185). National Bureau of Economic Research.

Ball, L., Jalles, J.T., Loungani, P. (2015). Do forecasters believe in Okun's Law? An assessment of unemployment and output forecasts. International Journal of Forecasting, 31(1), 176-184.

Ball, L., Leigh, D., Loungani, P. (2017). Okun's law: Fit at 50? Journal of Money, Credit and Banking, 49(7), 1413-1441. 
Bassanetti, A., Caivano, M., Locarno, A. (2010). Modelling Italian potential output and the output gap (No. 771). Bank of Italy, Economic Research and International Relations Area.

Beckerman, W. Jenkinson, T. (1986), What stopped the inflation? Unemployment of commodity prices?, Economic Journal, 96, pp. 39-54.

Billmeier, A. (2009) Ghostbusting: which output gap measure really matters? International Economics and Economic Policy, 6, 391-419.

Blanchard, O., Quah, D. (1989). The dynamic effects of aggregate supply and demand shocks. American Economic Review, 79(4), 655-673.

Blanchard, O. (2016). The Phillips Curve: Back to the '60s? American Economic Review, $106(5), 31-34$.

Blanchard, O. J., Cerutti, E. M., Summers, L. (2015). Inflation and Activity-Two Explorations and their Monetary Policy Implications. International Monetary Fund (No. 15/230).

Boone, L., Giorno, C., Meacci, M., Rae, D., Richardson, P., Turner, D. (2003). Estimating the structural rate of unemployment for the OECD countries. OECD Economic Studies, 2001(2), 171-216.

Bronfenbrenner, M., Holzman, F.D. (1963). Survey of Inflation Theory. American Economic Review 53(4): 593-661.

Busetta, G., Corso, D. (2008). La legge di Okun: asimmetrie e differenziali territoriali in Italia. Università politecnica delle Marche, Dipartimento di economia.

Busetta, G., Corso, D. (2012). Labor Productivity and Okun's Law: An Empirical Application to Italian Regional Panel Data. Rivista italiana degli economisti, 17(2), 279-298.

Cazes, S., Verick, S. (2011). What has happened to Okun's law in the United States and Europe? Insights from the global financial and economic crisis and long-term trends. The global crisis: Causes, responses and challenges, International Labour Office

Celi, G., Ginzburg, A., Guarascio, D., Simonazzi, A. (2017). Crisis in the European monetary union: a core-periphery perspective. Routledge

Ciucci, M., Zoppè, A. (2016). Potential output estimates and their role in the EU fiscal policy surveillance. Briefing Document for the European Parliament (PE574. 407).

Cohen, P. (2018), Paychecks Lag as Profits Soar, and Prices Erode Wage Gains, New York Times, available at https:/www.nytimes.com/2018/07/13/business/economy/wages-workers-profits.html

Congressional Budget Office (2014), Revisions to CBO's Projection of Potential Output Since 2007, February.

Congressional Budget Office (2019), The Budget and Economic Outlook: 2019 to 2029, January.

Costantini, O. (2015). The Cyclically Adjusted Budget: History and Exegesis of a Fateful Estimate. Institute for New Economic Thinking Working Paper, Working Paper No. 24, available at https://www.ineteconomics.org/uploads/papers/WP24_Costantini_1.pdf

Cotis, J. P., Elmeskov, J., Mourougane, A. (2004). Estimates of potential output: benefits and pitfalls from a policy perspective. The euro area business cycle: stylized facts and measurement issues, Centre for Economic Policy Research, 35-60.

Cross, R. (1995), Is the natural rate hypothesis consistent with hysteresis?, in Cross (1995) The natural rate of unemployment, Cambridge: Cambridge University Press.

D’Auria, F., Denis, C., Havik, K., McMorrow, K., Planas, C., Raciborski, R., Röger, W. Rossi, A. (2010). The Production Function Methodology For Calculating Potential Growth Rates \& Output Gaps, European Economy Economic Papers, No 420. 
DeLong, J.B. (1996). Keynesianism, Pennsylvania Avenue style: Some economic consequences of the Employment Act of 1946. Journal of Economic Perspectives, 10(3), 41-53.

Dosi, G., Pereira, M. C., Roventini, A., Virgillito, M. E. (2018). Causes and consequences of hysteresis: Aggregate demand, productivity and employment. Industrial and Corporate Change, 1, 30 .

Erceg, C. J., Levin, A. T. (2014). Labor force participation and monetary policy in the wake of the Great Recession. Journal of Money, Credit and Banking, 46(S2), 3-49.

European Central Bank (2011), Trends in potential output, Monthly Bulletin, ECB, January, pp. 73-85.

European Central Bank (2011) Monthly Bulletin, November, pp. 51-55.

European Commission (2009), "Impact of the current economic and financial crisis on potential output", European Economy Occasional Papers No 49, June.

European Commission (2016), Communication from the Commission on 2017 Draft Budgetary Plans: Overall Assessment

Fabiani, S., Mestre, R. (2000), Alternative measures of the NAIRU in the euro area: estimates and assessment, ECB Working Paper, No. 17, European Central Bank (ECB), Frankfurt a. M.

Fabiani, S., Mestre, R. (2004). A system approach for measuring the euro area NAIRU. Empirical Economics, 29(2), 311-341.

Fatás, A. (2018). Fiscal policy, potential output and the shifting goalposts. CEPR Discussion Paper No. DP13149

Fazzari, S., Ferri, P., Variato, A. (2018). Demand-led growth and accommodating supply (No. 15-2018). IMK at the Hans Boeckler Foundation, Macroeconomic Policy Institute.

Fioramanti, M., Padrini, F., Pollastri, C. (2015). La stima del PIL potenziale e dell'output gap: analisi di alcune criticità. Ufficio Parlamentare di Bilancio, Nota di lavoro, (1).

Forder, J. (2014), Macroeconomics and the Phillips Curve Myth., Oxford University Press.

Franz, W. (2005) Will the (German) NAIRU please stand up?, Zentrum für Europäische Wirtschaftsforschung, Discussion Paper no. 03-35.

Freeman, D. G. (2000). Regional tests of Okun's law. International Advances in Economic Research, 6(3), 557-570.

Freeman, D. G. (2001). Panel tests of Okun's law for ten industrial countries. Economic Inquiry, 39(4), 511-523.

Galbraith, J. K. (1997), Time to Ditch the NAIRU, Journal of Economic Perspectives, 11, pp. 93-108.

Garavan, S., (2017), Okun's law: an empirical investigation into Eurozone growth and unemployment, The Student Economic Review, Vol. XXXI

Giorno, C., Richardson, P., Roseveare, D., Van den Noord, P. (1995). Estimating Potential Output, Output Gaps and Structural Budget Balances (No. 152). OECD Publishing.

Girardi, D., Paternesi Meloni, W., Stirati, A. (2017). Persistent Effects of Autonomous Demand Expansions. Institute for New Economic Thinking, Working Paper No. 70, available at https://www.ineteconomics.org/uploads/papers/WP_70-Stirati-DemandExpansion.pdf

Gordon, R. J. (1970). Prices in 1970: The Horizontal Phillips Curve?. Brookings Papers on Economic Activity, 1970(3), 449-458.

Gordon, R. J. (1984). Unemployment and Potential Output in the 1980s. Brookings Papers on Economic Activity, 15(2), 537-568.

Gordon, R. J. (1997). The time-varying NAIRU and its implications for economic policy. Journal of economic Perspectives, 11(1), 11-32. 
Gordon, R. J. (2010). Okun's Law, Productivity Innovations, and Conundrums in Business Cycle Dating, Northwestern University, January.

Gordon, R. J. (2014). A new method of estimating potential real GDP growth: Implications for the labor market and the debt/GDP ratio (No. w20423). National Bureau of Economic Research.

Hall, Robert E., Taylor, John B. (1988), Macroeconomics, second edition, (New York: Norton \& Co.).

Heimberger, P., Kapeller, J. (2016). The performativity of potential output: Pro-cyclicality and path dependency in coordinating European fiscal policies. Institute for New Economic Thinking, Working Paper No. 50, available at https://www.ineteconomics.org/uploads/papers/WP_50_Haimberger_Kapeller.pdf

Horn, G., Logeay, C., Tober, S. (2007). Methodological Issues of Medium-Term Macroeconomic Projections-The Case of Potential Output (No. 4/2007). IMK Study.

Kargi, B. (2016). Okun's Law and Long Term Co-Integration Analysis for OECD Countries (1987-2012). EMAJ: Emerging Markets Journal, 6(1), 39-46

Knotek II, E. S. (2007). How useful is Okun's law? Economic Review-Federal Reserve Bank of Kansas City, 92(4), 73.

Kreishan, F. M. (2011). Economic growth and unemployment: An empirical analysis. Journal of Social Sciences, 7(2), 228-231.

Krugman, P. (2018), The Economic Future Isn't What It Used to Be (Wonkish), The New York Times, available at

https://www.nytimes.com/2018/09/30/opinion/the-economic-future-isnt-what-it-usedto-be-wonkish.html

Jašová, M., Moessner, R., Takáts, E. (2018). Domestic and Global Output Gaps as Inflation Drivers: What Does the Phillips Curve Tell? CESifo Working Paper. (No. 7337).

International Monetary Fund (2006), World Economic Outlook, April.

Ladiray, D., Mazzi, G. L., Sartori, F. (2003). Statistical methods for potential output estimation and cycle extraction. Office for Official Publications of the European Communities.

Lal, I., Muhammad, S. D., Jalil, M. A., Hussain, A. (2010). Test of Okun's Law in Some Asian Countries Co-Integration Approach. European Journal of Scientific Research, 40(1), 73-80.

Lanzafame, M. (2009). Is regional growth in Italy endogenous?. Regional Studies, 43(8), 1001-1013.

Lee, J. (2000). The robustness of Okun's law: Evidence from OECD countries. Journal of macroeconomics, 22(2), 331-356.

Leonhart, D. (2018), For Wages, a Trump Slump, The New York Times, available at https://www.nytimes.com/2018/08/05/opinion/columnists/trump-real-wages-inflationworkers-economy.html

Lim, G. C., Dixon, R., van Ours, J. J. (2018). Beyond Okun's Law: Output Growth and Labor Market Flows (No. 18-097/V). Tinbergen Institute.

Malley, J., Molana, H. (2008). Output, unemployment and Okun's law: Some evidence from the G7. Economics Letters, 101(2), 113-115.

Martin, B. (2011) Is the British economy supply constrained? A critique of productivity pessimis, Centre for Business Research and UK-IRC.

Mayes, D. G., Viren, M. (2002). Asymmetry and the Problem of Aggregation in the Euro Area. Empirica, 29(1), 47-73. 
Meyer, B., Tasci, M. (2012). An unstable Okun's Law, not the best rule of thumb. Economic Commentary, (June).

Micallef, B. (2016). Empirical estimates of Okun's Law in Malta. Applied Economics and Finance, 4(1), 138-148

Ministero dell'Economia e delle Finanze (2016), Economic and Financial Document 2016, Section I: Italy's Stability Programme.

Moosa, I. A. (1997). A cross-country comparison of Okun's coefficient. Journal of comparative economics, 24(3), 335-356.

Moosa, I. (2008). Economic growth and unemployment in Arab countries: Is Okun's law valid?. Journal of Development and Economic Policies, 10(2), 7-24.

Musso, A., Stracca, L., van Dijk, D. (2009). Instability and Nonlinearity in the Euro-Area Phillips Curve. International Journal of Central Banking, 5(2), 181-212.

Oksanen, H. (2018). New Output Gap Estimates for Assessing Fiscal Policy with Lessons for Euro Area Reform (No. 7287). CESifo Working Paper.

Okun, A. (1962), Potential GNP: Its measurement and significance, Proceedings of the American Statistical Association, Business and Economic Statistics Section, ASA, Washington, 98-104.

Okun, A. M. (1973). Upward mobility in a high-pressure economy. Brookings Papers on Economic Activity, 1973(1), 207-261.

Paldman M. (1987), How much does one percent of growth change the unemployment rate? European Economic Review, 31, pp. 306-313.

Palley T.I. (1993), Okun's law and the asymmetric and changing cyclical behaviour of the USA economy, International Review of Applied Economics, 7, pp. 144-62

Palumbo, A. (2015) Studying Growth in the Modern Classical Approach: Theoretical and Empirical Implications for the Analysis of Potential Output, Review of Political Economy, 27:3, 282-307

Peach, R., Rich, R. W., Cororaton, A. (2011). How does slack influence inflation? Current Issues in Economics and Finance, 17(June).

Perman, R., Tavera, C. (2005). A cross-country analysis of the Okun's law coefficient convergence in Europe. Applied Economics, 37(21), 2501-2513.

Pesaran, H., R. Smith (1995), The natural rate hypothesis and its testable implications, in Cross (1995), The natural rate of unemployment, Cambridge: Cambridge University Press.

Prachowny, M. F. (1993). Okun's law: theoretical foundations and revised estimates. The review of Economics and Statistics, 331-336.

Reifschneider, D., Wascher, W., Wilcox, D. (2015). Aggregate supply in the United States: recent developments and implications for the conduct of monetary policy. IMF Economic Review, 63(1), 71-109.

Richardson, P., Boone, L., Giorno, C., Meacci, M., Rae, Turner, D. (2000) The concept, policy use and measurement of structural unemployment: estimating a time-varying NAIRU across 21 OECD countries, OECD Economics Department Working Papers, no. 250 .

Sadiku, M., Ibraimi, A., Sadiku, L. (2015). Econometric estimation of the relationship between unemployment rate and economic Growth of FYR of Macedonia. Procedia Economics and Finance, 19, 69-81.

Salvati, L. (2015). Space matters: Reconstructing a Local-scale Okun's Law for Italy. International Journal of Latest Trends in Finance and Economic Sciences, 5(1), 833.

Schreiber S. Wolters, J. (2007) The long-run Phillips curve revisited: is the NAIRU framework data-consistent?, Journal of Macroeconomics, 29, pp. 355-367. 
Schwarzer J.A. (2018) Retrospectives Cost-Push and Demand-Pull Inflation: Milton Friedman and the "Cruel Dilemma", Journal of Economic Perspectives, 32(1), 195-210.

Serrano, F. (2006), Mind the Gap: Hysteresis, Inflation Dynamics and the Sraffian Supermultiplier, available at http://www.ie.ufrj.br/datacenterie/pdfs/download/texto_10_10.pdf

Stirati, A. (2001), Inflation, Unemployment and Hysteresis: an alternative view, Review of Political Economy, 13, 427-51.

Stirati, A., Paternesi Meloni, W. (2018). A short story of the Phillips curve: from Phillips to Friedman... and back?. Review of Keynesian Economics, 6(4), 493-516.

Sögner, L., Stiassny, A. (2002). An analysis on the structural stability of Okun's law--a cross-country study. Applied Economics, 34(14), 1775-1787.

Solow, R.M. (1986), Unemployment: Getting the Questions Right, Economica, 53, Suppl., pp. S23-S34.

Solow, R. (2000). Unemployment in the United States and in Europe-A Contrast and the Reasons (No. 231). CESifo working paper.

Solow, R. (2018). A theory is a sometime thing. Review of Keynesian Economics, 6(4), 421-424.

Stock, L., Vogler-Ludwig, K. (2010). NAIRU and Okun's law-The macro-economy in a nutshell. Thematic Paper for the European Commission Directorate General for Employment, Social Affairs and Equal Opportunities, European Employment Observatory. Munich.

Storm, S. (2017). The New Normal: Demand, Secular Stagnation and the Vanishing Middle-Class. Institute for New Economic Thinking, Working Paper No. 55, available at https://www.ineteconomics.org/uploads/papers/WP_55-Storm-The-New-Normal.pdf

Storm, S. (2018), With Official Unemployment This Low, Why Are Wages Rising So Slowly? Institute for New Economic Thinking Blog, available at https://www.ineteconomics.org/perspectives/blog/with-official-unemployment-this-lowwhy-are-wages-rising-so-slowly

Summers, L. (2017). America needs its unions more than ever. Financial Times, 3, available at https://www.ft.com/content/180127da-8e59-11e7-9580c651950d3672

Villaverde, J., Maza, A. (2009). The robustness of Okun's law in Spain, 1980-2004: Regional evidence. Journal of Policy Modeling, 31(2), 289-297.

Virén, M. (2001). The Okun curve is non-linear. Economics letters, 70(2), 253-257.

Weber, C. E. (1995). Cyclical output, cyclical unemployment, and Okun's coefficient: A new approach. Journal of applied econometrics, 10(4), 433-445. 


\section{APPENDIX A1 - Analysis of residuals}

\section{A1.1. ARMAX model}

Figure A1.1 - Residuals versus fitted values plot

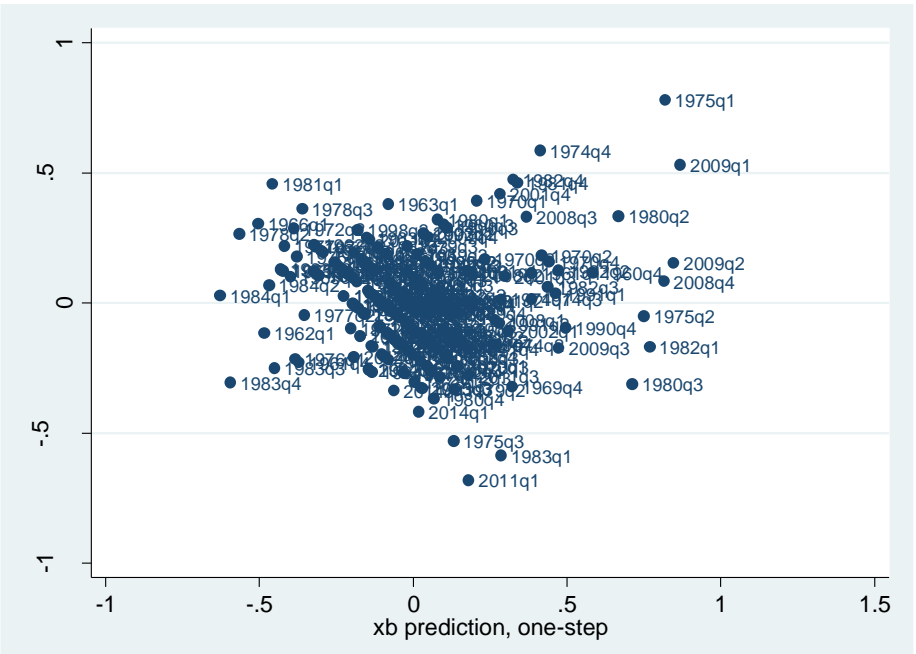

Figure A1.2 - Residuals and predicted values

a. Residuals with respect to time

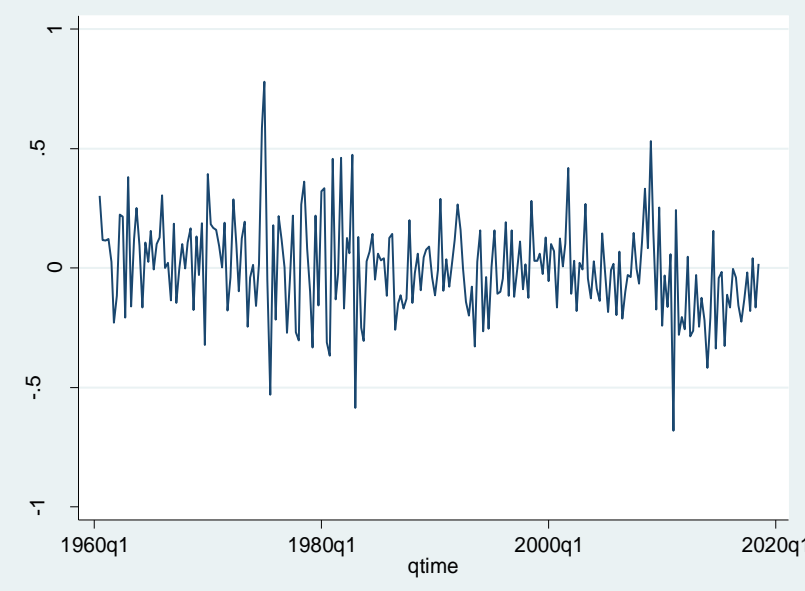

b. Unemployment and predicted values

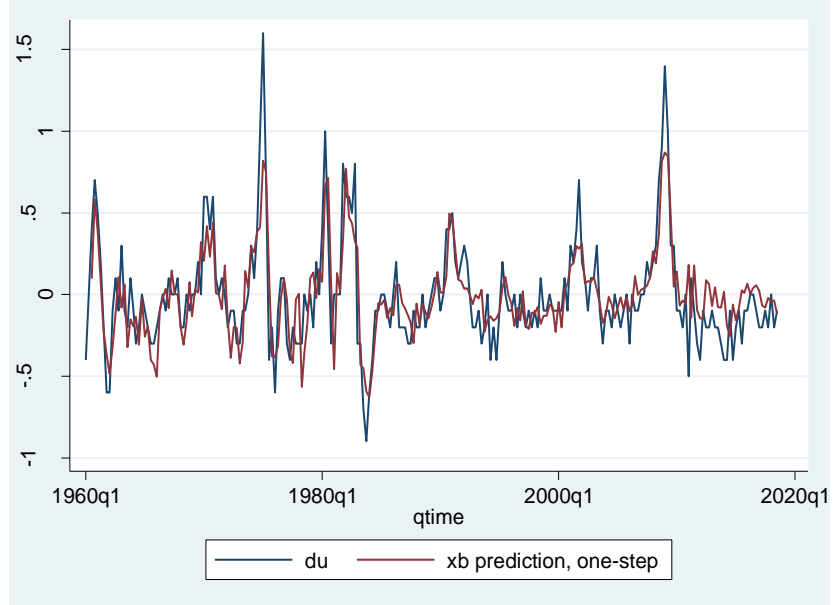

Figure A1.3 - ACF and PACF of residuals

a. $A C F$

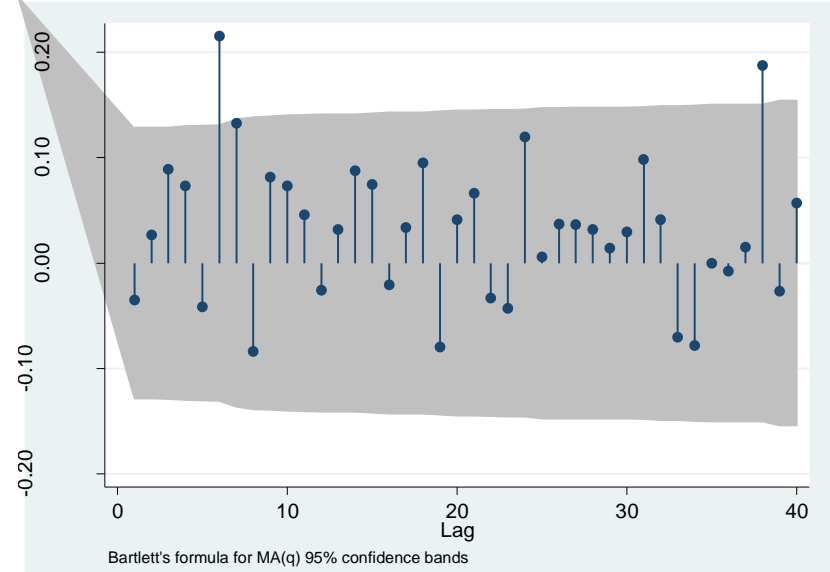

b. $P A C F$

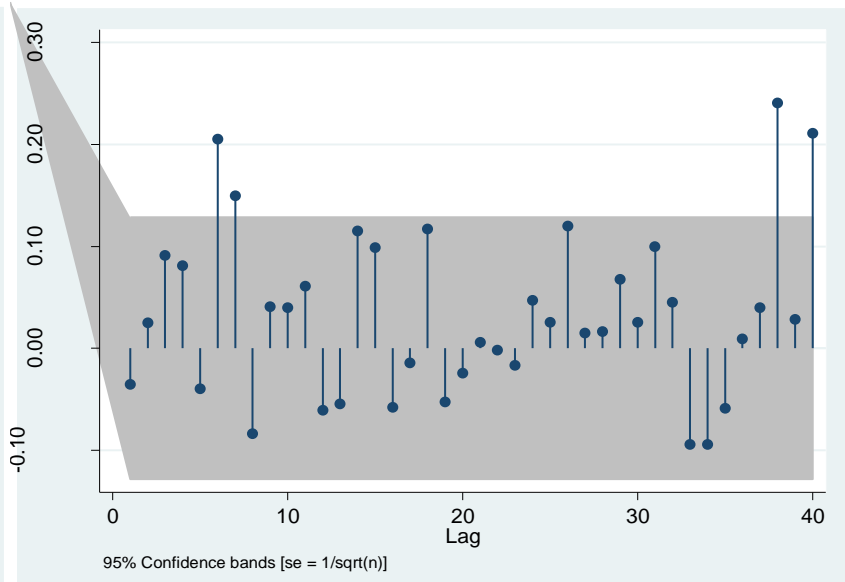


Shapiro-Wilk test for normality:

Shapiro-Wilk w test for normal data

\begin{tabular}{r|ccccr} 
Variable & Obs & W & V & z & Prob>z \\
\hline$e$ & 233 & 0.98704 & 2.210 & 1.839 & 0.03297
\end{tabular}

The null hypothesis of normal distribution is rejected.

\section{A1.2. ARMAX model with structural break}

Figure A1.4 - Residuals versus fitted values plot

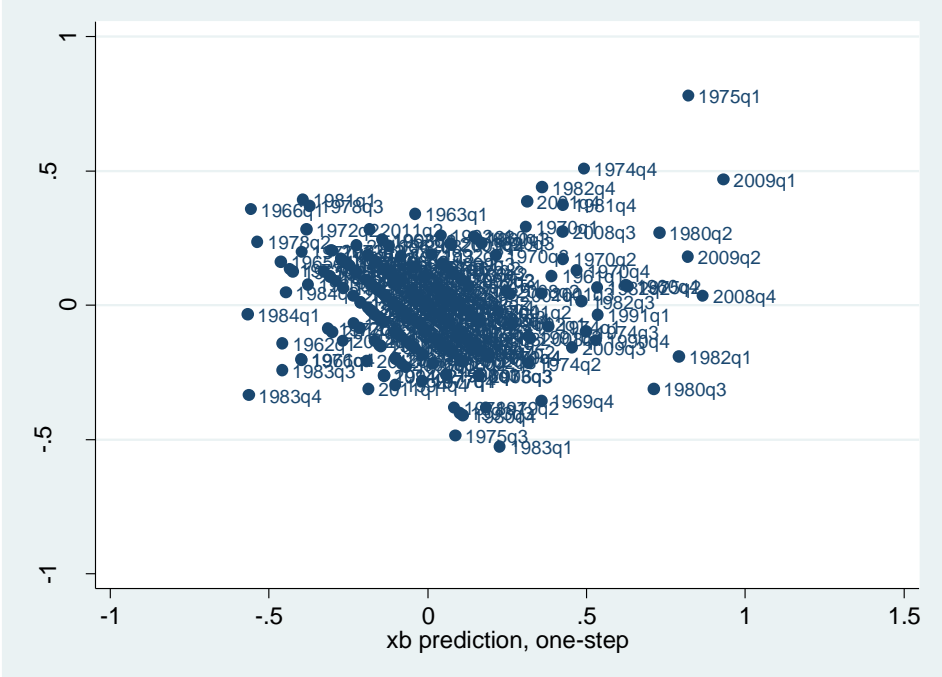

Figure A1.5 - Residuals and predicted values

a. Residuals with respect to time

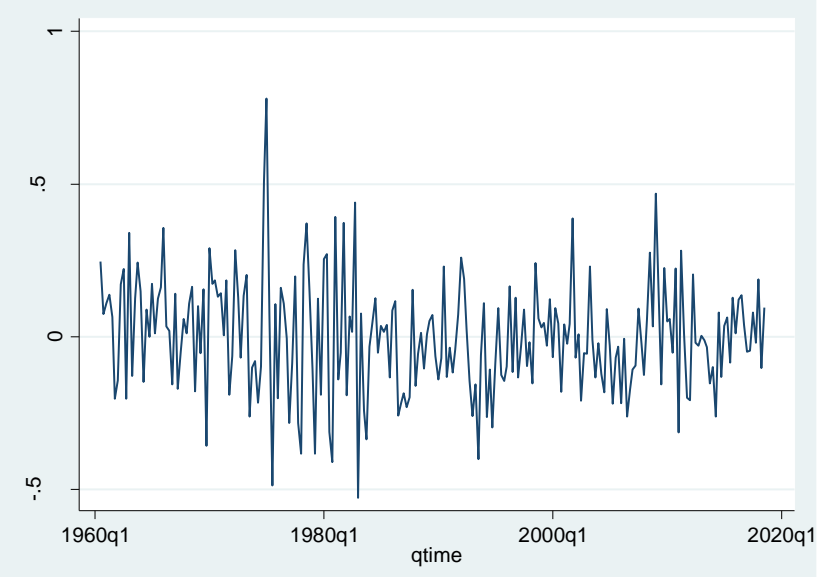

b. Unemployment and predicted values

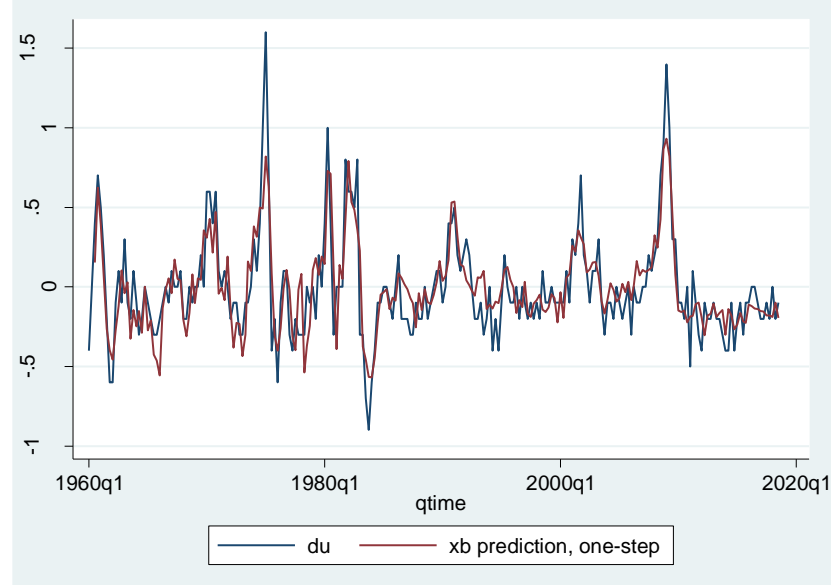


Figure A1.6 - ACF and PACF of residuals
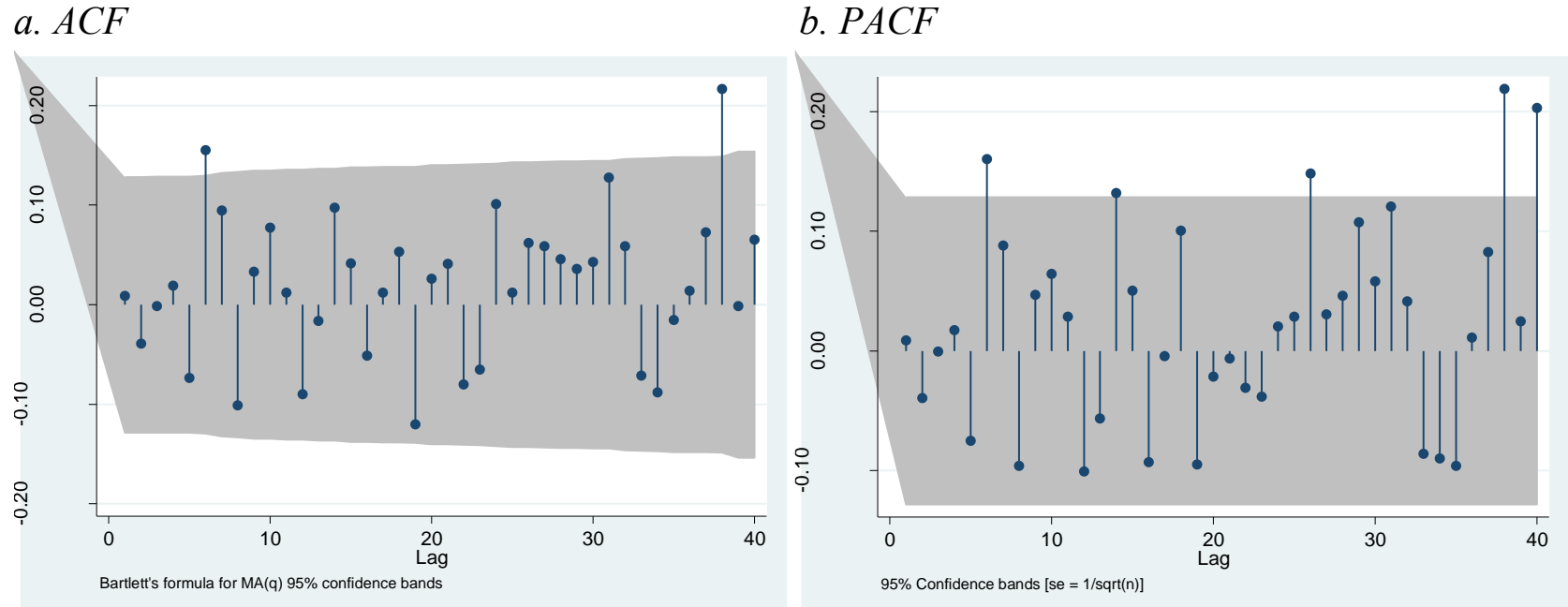

Shapiro-Wilk test for normality:

\begin{tabular}{r|ccccr} 
Variable & Obs & W & V & z & Prob>z \\
\hline e & 233 & 0.98995 & 1.713 & 1.248 & 0.10603
\end{tabular}

The null hypothesis of normal distribution is accepted.

\section{A1.3. ARMAX model with asymmetries}

Figure A1.7 - Residuals versus fitted values plot

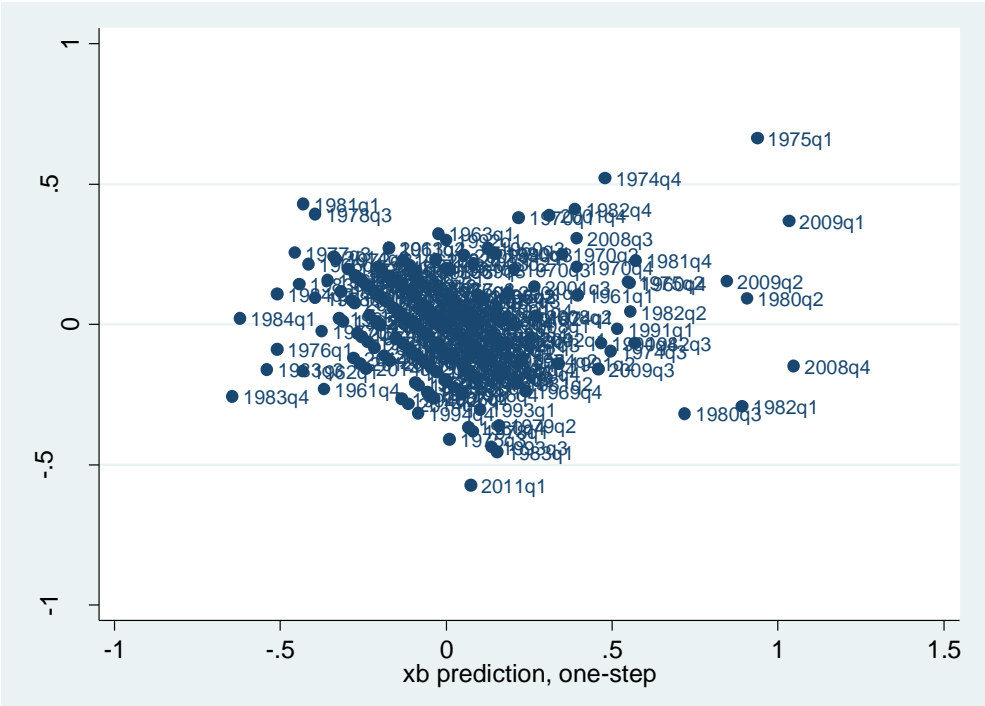


Figure A1.8 - Residuals and predicted values

a. Residuals with respect to time

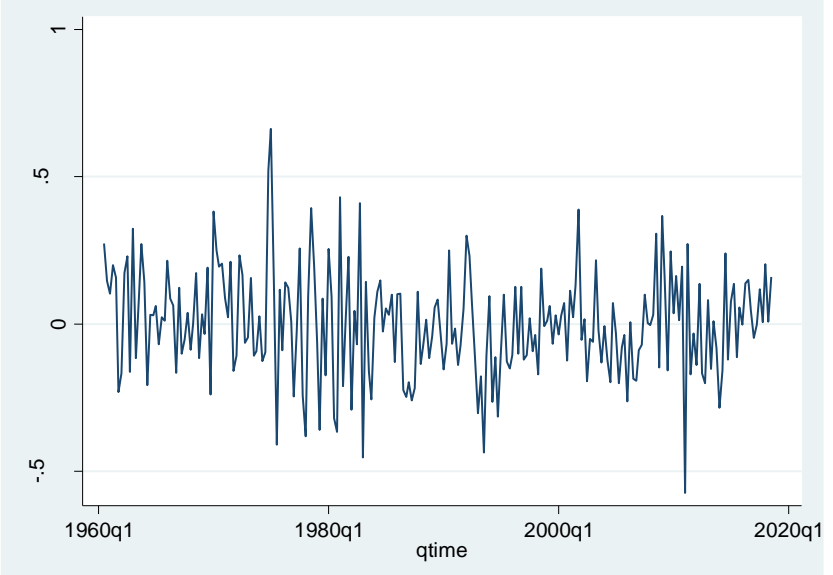

b. Unemployment and predicted values

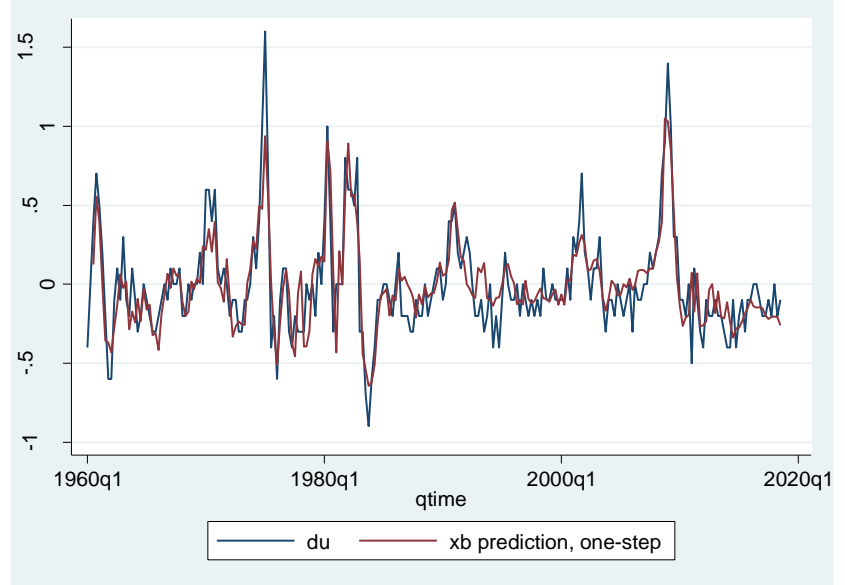

Figure A1.9 - ACF and PACF of residuals

a. $A C F$

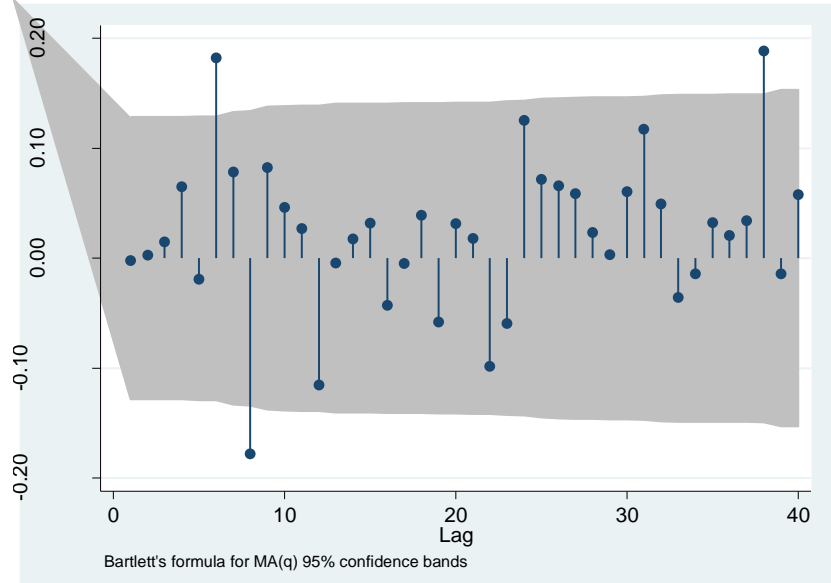

b. $P A C F$

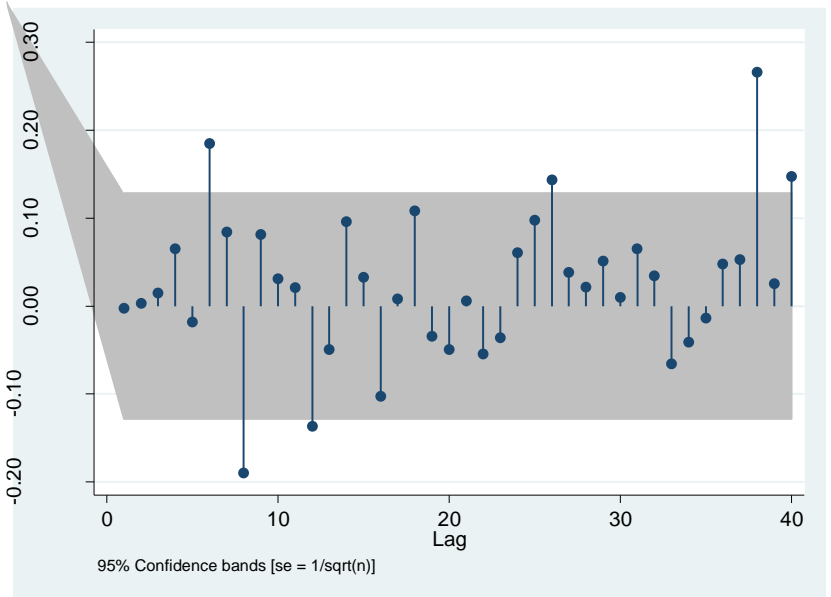

Shapiro-Wilk test for normality:

Shapiro-Wilk w test for normal data

\begin{tabular}{r|ccccr} 
Variable & Obs & W & V & z & Prob>z \\
\hline e & 233 & 0.99440 & 0.955 & -0.106 & 0.54220
\end{tabular}

The null hypothesis of normal distribution is accepted. 
APPENDIX A2 - Alternative definition of unemployment ranges

\begin{tabular}{|c|c|c|c|}
\hline Equal-size ranges & $\begin{array}{c}\text { percentiles } \\
\text { (approximate) }\end{array}$ & $\begin{array}{c}\text { range of } \\
\text { unemployment rates } \\
\text { (percent) }\end{array}$ & $\begin{array}{c}\text { number of } \\
\text { observations }\end{array}$ \\
\hline low unemployment & $0-33$ & $0-5.2$ & 80 \\
\hline medium unemployment & $33-67$ & $5.3-6.6$ & 84 \\
\hline high unemployment & $67-100$ & $6.7-$ & 72 \\
\hline Extreme ranges & $\begin{array}{c}\text { percentiles } \\
\text { (approximate) }\end{array}$ & $\begin{array}{c}\text { range of } \\
\text { unemployment rates } \\
\text { (percent) }\end{array}$ & $\begin{array}{c}\text { number of } \\
\text { observations }\end{array}$ \\
\hline low unemployment & $0-15$ & $0-4.4$ & 37 \\
\hline medium unemployment & $15-85$ & $4.5-7.5$ & 161 \\
\hline high unemployment & $85-100$ & 7.6- & 38 \\
\hline
\end{tabular}

Table A2.2 - Estimation with the two alternative definitions of ranges (comparison)

\begin{tabular}{|l|l|l|l|l|l|l|}
\hline & \multicolumn{4}{|l|}{ Equal-size ranges model } & \multicolumn{3}{l|}{ Extreme ranges model } \\
& \multicolumn{1}{|c|}{$u_{\text {LOW }}$} & $u_{\text {MEDIUM }}$ & $u_{H I G H}$ & $u_{\text {LOW }}$ & $u_{\text {MEDIUM }}$ & $u_{H I G H}$ \\
\hline$g y_{t}$ & $-0.10^{* * *}$ & $-0.16^{* * *}$ & $-0.26^{* * *}$ & $-0.11^{* * *}$ & $-0.17^{* * *}$ & $-0.37^{* * *}$ \\
\hline$g y_{t-1}$ & $-0.098^{* * *}$ & $-0.14^{* * *}$ & $-0.14^{* * *}$ & $-0.10^{* * *}$ & $-0.12^{* * *}$ & $-0.14^{* * *}$ \\
\hline$g y_{t-2}$ & $-0.09^{* * *}$ & $-0.09^{* * *}$ & $-0.09^{* *}$ & $0.05^{*}$ & $-0.08^{* * *}$ & $-0.09^{*}$ \\
\hline Constant term & $-0.15^{* *}$ & -0.07 & $0.11^{* *}$ & $-0.21^{* *}$ & $-0.16^{* *}$ & $0.16^{* *}$ \\
\hline break & $0.28^{* * *}$ & & $0.29^{* * *}$ & \\
\hline$\Delta u_{t-1}$ & $0.17^{* *}$ & \multicolumn{7}{|l}{} \\
\hline Cumulated & $\mathbf{- 0 . 2 9}$ & $\mathbf{- 0 . 3 9}$ & $\mathbf{- 0 . 4 9}$ & $\mathbf{- 0 . 2 7}$ & $\mathbf{- 0 . 3 6}$ & $\mathbf{- 0 . 5 5}$ \\
\hline
\end{tabular}

Significance levels: $* * * p<0.01,{ }^{* *} \mathrm{p}<0.05,{ }^{*} \mathrm{p}<0.1$

Figure A2.1 - Residuals versus fitted values plot

a. Equal-size ranges model

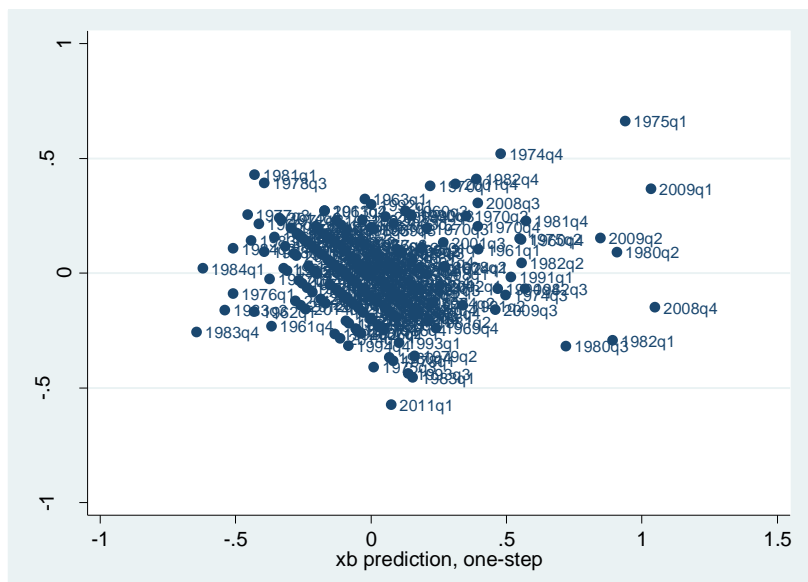

b. Extreme ranges model

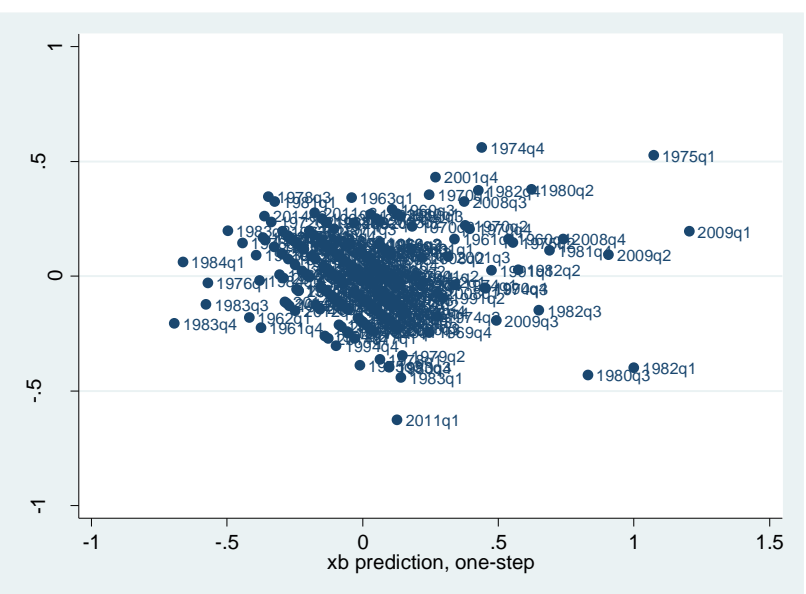


APPENDIX A3 - Outliers (alternative models with dummies)

A3.1. ARMAX model with asymmetries (equal-size ranges)

Table A3.1 Comparison of different models with and without dummies for outliers

\begin{tabular}{|c|c|c|c|c|c|c|c|c|c|c|c|c|}
\hline \multirow[t]{2}{*}{$\begin{array}{l}\text { Varia } \\
\text { bles }\end{array}$} & \multicolumn{3}{|c|}{$\begin{array}{l}\text { Equal-size } \\
\text { model }\end{array}$} & \multicolumn{3}{|c|}{$\begin{array}{l}\text { Model with one dummy } \\
(1975 q 1)\end{array}$} & \multicolumn{3}{|c|}{$\begin{array}{l}\text { Model with one dummy } \\
\text { (2011q1) }\end{array}$} & \multicolumn{3}{|c|}{$\begin{array}{l}\text { Model with two dummies } \\
(1975 q 1-2011 q 1)\end{array}$} \\
\hline & $u_{L O W}$ & $u_{M E D I U}$ & $u_{H I G H}$ & $u_{L O W}$ & $u_{M E D I U M}$ & $u_{H I G H}$ & $u_{\text {LOW }}$ & $u_{M E D I U}$ & $u_{H I G H}$ & $u_{L O W}$ & $u_{M E D I U}$ & $u_{H I G H}$ \\
\hline$g y_{t}$ & $\begin{array}{l}- \\
0.10 * \\
* *\end{array}$ & $\begin{array}{l}- \\
0.16^{*} \\
* *\end{array}$ & $\begin{array}{l}- \\
0.26 * \\
* *\end{array}$ & $\begin{array}{l}- \\
0.10^{*} \\
* *\end{array}$ & $\begin{array}{l}- \\
0.16^{* *} \\
*\end{array}$ & $\begin{array}{l}- \\
0.24 * \\
* *\end{array}$ & $\begin{array}{l}- \\
0.10 * \\
* *\end{array}$ & $\begin{array}{l}- \\
0.16^{*} \\
* *\end{array}$ & $\begin{array}{l}- \\
0.27 * \\
* *\end{array}$ & $\begin{array}{l}- \\
0.10 * \\
* *\end{array}$ & $\begin{array}{l}- \\
0.16^{*} \\
* *\end{array}$ & $-0.25 * * *$ \\
\hline$g y_{t-1}$ & $\begin{array}{l}- \\
0.10 * \\
* *\end{array}$ & $\begin{array}{l}- \\
0.14 * \\
* *\end{array}$ & $\begin{array}{l}- \\
0.14 * \\
* *\end{array}$ & $\begin{array}{l}- \\
0.10^{*} \\
* *\end{array}$ & $\begin{array}{l}- \\
0.14 * * \\
*\end{array}$ & $\begin{array}{l}- \\
0.15 * \\
* *\end{array}$ & $\begin{array}{l}- \\
0.10 * \\
* *\end{array}$ & $\begin{array}{l}- \\
0.14 * \\
* *\end{array}$ & $\begin{array}{l}- \\
0.14 * \\
* *\end{array}$ & $\begin{array}{l}- \\
0.10 * \\
* *\end{array}$ & $\begin{array}{l}- \\
0.14 * \\
* *\end{array}$ & $-0.14 * * *$ \\
\hline$g y_{t-2}$ & $\begin{array}{l}- \\
0.09 * \\
* *\end{array}$ & $\begin{array}{l}- \\
0.09 * \\
* *\end{array}$ & $\begin{array}{l}- \\
0.09 * \\
*\end{array}$ & $\begin{array}{l}- \\
0.09 * \\
* *\end{array}$ & $\begin{array}{l}- \\
0.09 * * \\
*\end{array}$ & $\begin{array}{l}- \\
0.08^{*} \\
*\end{array}$ & $\begin{array}{l}- \\
0.08 * \\
* *\end{array}$ & $\begin{array}{l}- \\
0.09 * \\
* *\end{array}$ & $\begin{array}{l}- \\
0.08 * \\
*\end{array}$ & $\begin{array}{l}- \\
0.09 * \\
* *\end{array}$ & $\begin{array}{l}- \\
0.09 * \\
* *\end{array}$ & $-0.07 * *$ \\
\hline $\begin{array}{l}\text { Const } \\
\text { ant } \\
\text { term }\end{array}$ & $\begin{array}{l}- \\
0.15 * \\
*\end{array}$ & -0.07 & $\begin{array}{l}0.11 * \\
*\end{array}$ & $\begin{array}{l}- \\
0.12 * \\
*\end{array}$ & -0.04 & $0.09 *$ & $\begin{array}{l}- \\
0.16 * \\
*\end{array}$ & -0.08 & $\begin{array}{l}0.14^{*} \\
* *\end{array}$ & $\begin{array}{l}- \\
0.13 * \\
*\end{array}$ & -0.05 & $0.11 * * *$ \\
\hline break & \multicolumn{3}{|c|}{$0.28 * * *$} & \multicolumn{3}{|c|}{$0.28 * * *$} & \multicolumn{3}{|c|}{$0.27 * * *$} & \multicolumn{3}{|c|}{$0.26 * * *$} \\
\hline $\begin{array}{l}\text { D75q } \\
1\end{array}$ & & & & \multicolumn{3}{|c|}{$0.71 * * *$} & & & & \multicolumn{3}{|c|}{$0.67 * * *$} \\
\hline $\begin{array}{l}\mathrm{D} 11 \mathrm{q} \\
1\end{array}$ & & & & & & & \multicolumn{3}{|c|}{$-0.64 * * *$} & \multicolumn{3}{|c|}{$-0.60 * * *$} \\
\hline$\Delta u_{t-1}$ & \multicolumn{3}{|c|}{$0.17 * *$} & \multicolumn{3}{|l|}{0.12} & \multicolumn{3}{|c|}{$0.21 * *$} & \multicolumn{3}{|l|}{$0.16^{*}$} \\
\hline $\begin{array}{l}\text { Cumu } \\
\text { lated }\end{array}$ & -0.29 & -0.39 & -0.49 & -0.29 & -0.39 & -0.47 & -0.28 & -0.39 & -0.49 & -0.29 & -0.39 & -0.46 \\
\hline
\end{tabular}

Significance levels: $* * * p<0.01, * * p<0.05,{ }^{*} \mathrm{p}<0.1$ 
Figure A3.1 - Residuals versus fitted values plot

a. Equal-size ranges model

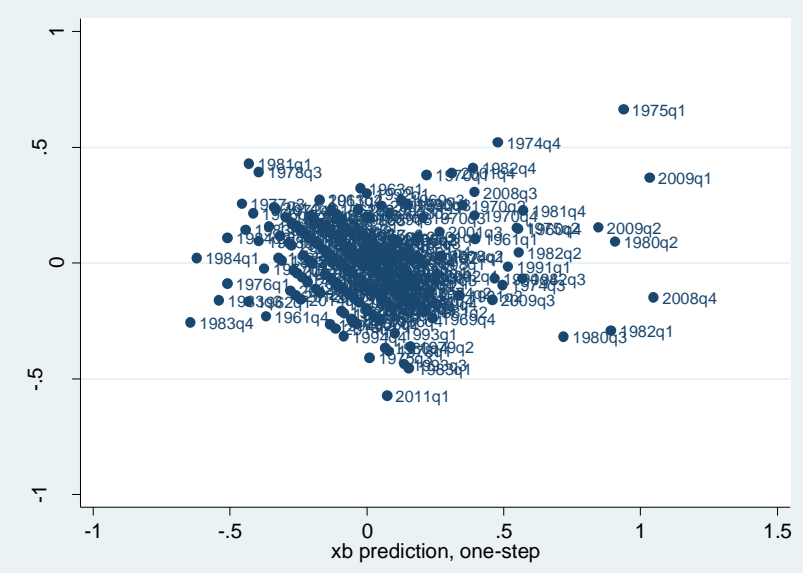

c. Model with one dummy (2011q1)

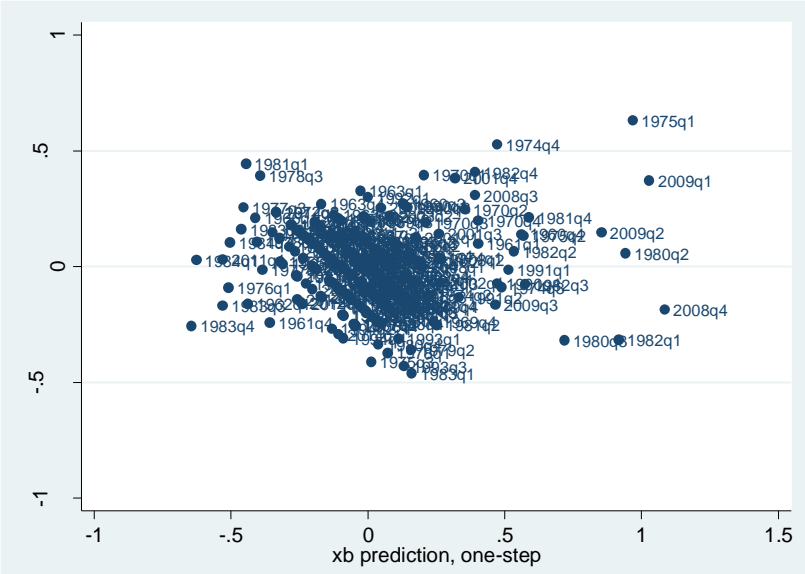

b. Model with one dummy (1975q1)

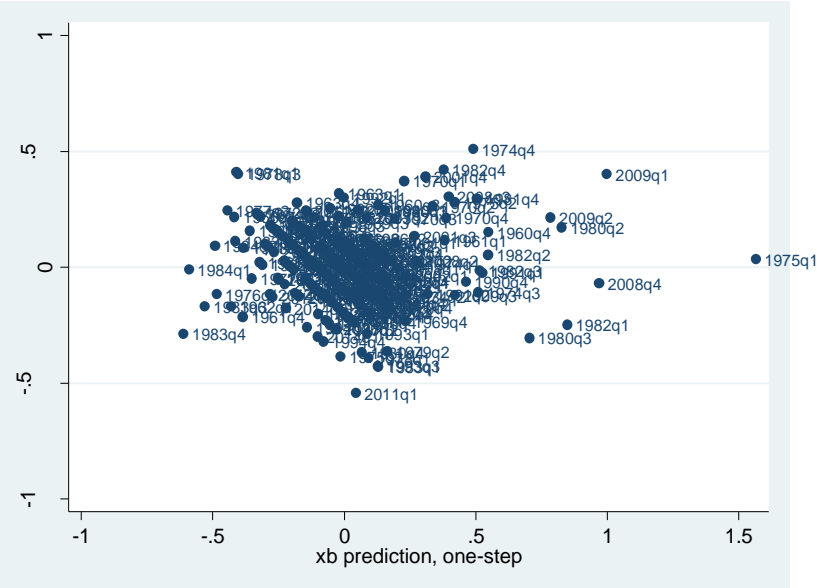

d. Model with two dummies (1975q1-2011q1)

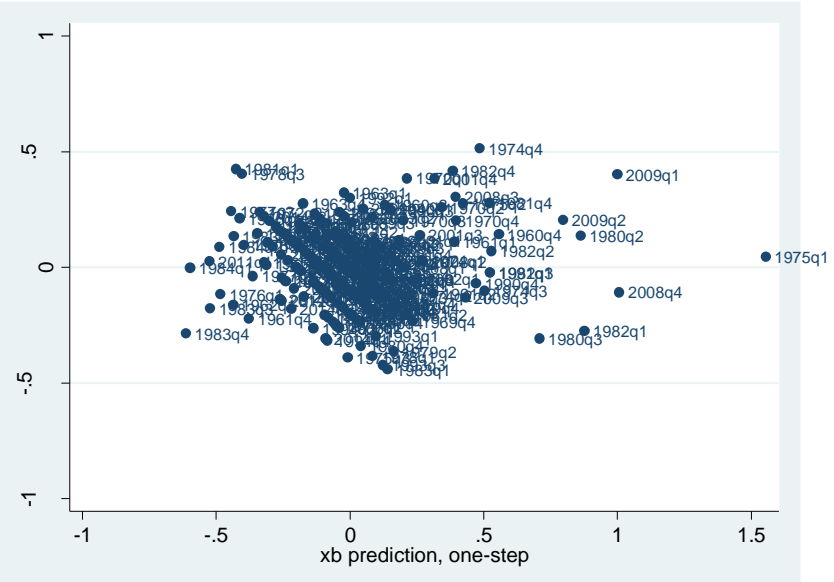




\section{A3.2. ARMAX model with asymmetries ("extreme ranges" hypothesis)}

\section{Table A3.2. Comparison of different models with and without dummies for outliers}

\begin{tabular}{|c|c|c|c|c|c|c|c|c|c|c|c|c|}
\hline \multirow[t]{2}{*}{$\begin{array}{l}\text { Varia } \\
\text { bles }\end{array}$} & \multicolumn{3}{|c|}{ Extreme ranges model } & \multicolumn{3}{|c|}{$\begin{array}{l}\text { Model with one } \\
\text { dummy }(1975 q 1)\end{array}$} & \multicolumn{3}{|c|}{$\begin{array}{l}\text { Model with one } \\
\text { dummy (2011q1) }\end{array}$} & \multicolumn{3}{|c|}{$\begin{array}{l}\text { Model with two } \\
\text { dummies } \\
\text { 2011q1) }\end{array}$} \\
\hline & $u_{L O W}$ & $u_{M E D I U}$ & $u_{H I G H}$ & $u_{L O W}$ & $u_{M E D I U}$ & $u_{H I G H}$ & $u_{L O W}$ & $u_{M E D I U}$ & $u_{H I G H}$ & $u_{L \square W}$ & $u_{M E D I U}$ & $u_{H I G H}$ \\
\hline$g y_{t}$ & $\begin{array}{l}- \\
0.11 * \\
* *\end{array}$ & $\begin{array}{l}- \\
0.17 * \\
* *\end{array}$ & $\begin{array}{l}- \\
0.37 * \\
* *\end{array}$ & $\begin{array}{l}- \\
0.11 * \\
* *\end{array}$ & $\begin{array}{l}- \\
0.17 * \\
* *\end{array}$ & $\begin{array}{l}- \\
0.27 * \\
* *\end{array}$ & $\begin{array}{l}- \\
0.11 * \\
* *\end{array}$ & $\begin{array}{l}- \\
0.16^{*} \\
* *\end{array}$ & $\begin{array}{l}- \\
0.34 * \\
* *\end{array}$ & $\begin{array}{l}- \\
0.11 * \\
* *\end{array}$ & $\begin{array}{l}- \\
0.17 * \\
* *\end{array}$ & $\begin{array}{l}- \\
0.30 * \\
* *\end{array}$ \\
\hline$g y_{t-1}$ & $\begin{array}{l}- \\
0.10^{*} \\
* *\end{array}$ & $\begin{array}{l}- \\
0.12 * \\
* *\end{array}$ & $\begin{array}{l}- \\
0.14 * \\
* *\end{array}$ & $\begin{array}{l}- \\
0.10^{*} \\
* *\end{array}$ & $\begin{array}{l}- \\
0.12 * \\
* *\end{array}$ & $\begin{array}{l}- \\
0.16^{*} \\
* *\end{array}$ & $\begin{array}{l} \\
0.10 * \\
* *\end{array}$ & $\begin{array}{l}- \\
0.12 * \\
* *\end{array}$ & $\begin{array}{l}0.13 * \\
* *\end{array}$ & $\begin{array}{l}- \\
0.10^{*} \\
* *\end{array}$ & $\begin{array}{l}- \\
0.12 * \\
* *\end{array}$ & $\begin{array}{l}- \\
0.14 * \\
* *\end{array}$ \\
\hline$g y_{t-2}$ & $0.05^{*}$ & $\begin{array}{l}- \\
0.08 * \\
* *\end{array}$ & $-\overline{0} 09 *$ & $0.05^{*}$ & $\begin{array}{l}- \\
0.08^{*} \\
* *\end{array}$ & $0.08 *$ & & $\begin{array}{l}- \\
0.07 * \\
* *\end{array}$ & $0.08 *$ & $-\overline{0}{ }^{-}$ & $\begin{array}{l}- \\
0.08 * \\
* *\end{array}$ & \\
\hline $\begin{array}{l}\text { Const } \\
\text { ant } \\
\text { term }\end{array}$ & $\begin{array}{l}- \\
0.21 * \\
*\end{array}$ & $\begin{array}{l}- \\
0.16^{*} \\
*\end{array}$ & $\begin{array}{l}0.16^{*} \\
*\end{array}$ & $0.16^{*}$ & $0.12 *$ & $\begin{array}{l}0.13 * \\
*\end{array}$ & $\begin{array}{l}- \\
0.23 * \\
*\end{array}$ & $\begin{array}{l}- \\
0.05 * \\
*\end{array}$ & $\begin{array}{l}0.2^{* *} \\
*\end{array}$ & $\begin{array}{l}- \\
0.19 * \\
*\end{array}$ & $\begin{array}{l}- \\
0.05 * \\
*\end{array}$ & $\begin{array}{l}0.16^{*} \\
* *\end{array}$ \\
\hline$\Delta u_{t-1}$ & \multicolumn{3}{|l|}{$0.17 * *$} & \multicolumn{3}{|l|}{0.13} & \multicolumn{3}{|c|}{$0.22 * *$} & \multicolumn{3}{|l|}{$0.18 *$} \\
\hline Break & \multicolumn{3}{|c|}{$0.29 * * *$} & \multicolumn{3}{|c|}{$0.28 * * *$} & \multicolumn{3}{|c|}{$0.28 * * *$} & \multicolumn{3}{|c|}{$0.27 * * *$} \\
\hline d1975 & & & & \multicolumn{3}{|c|}{$0.62 * * *$} & & & & \multicolumn{3}{|c|}{$0.53 * * *$} \\
\hline $\mathrm{d} 2011$ & & & & & & & \multicolumn{3}{|c|}{$-0.71 * * *$} & \multicolumn{3}{|c|}{$-0.66 * * *$} \\
\hline $\begin{array}{l}\text { Cumu } \\
\text { lated }\end{array}$ & -0.27 & -0.36 & -0.55 & -0.27 & -0.37 & -0.51 & -0.21 & -0.36 & -0.55 & -0.26 & -0.36 & -0.44 \\
\hline
\end{tabular}

Significance levels: $* * * p<0.01, * * p<0.05,{ }^{*} \mathrm{p}<0.1$ 
Figure A3.2 - Residuals versus fitted values plot

a. Extreme ranges model

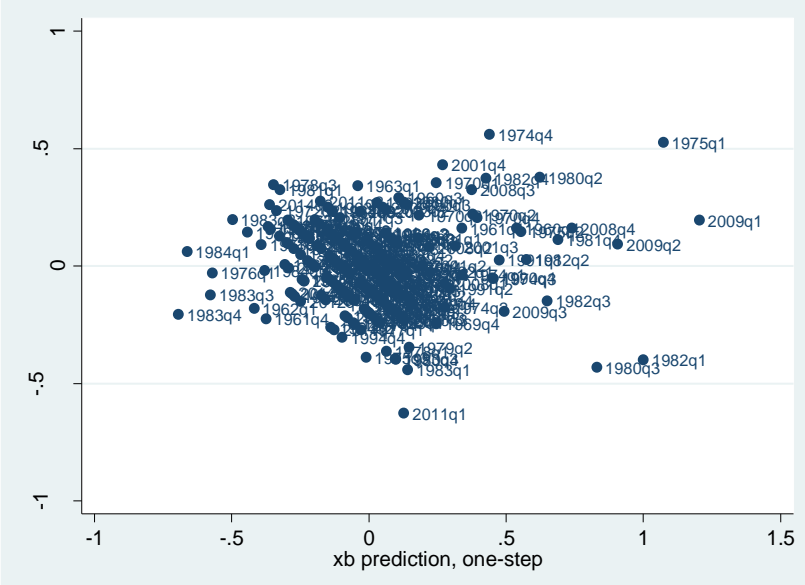

c. Model with one dummy (2011q1)

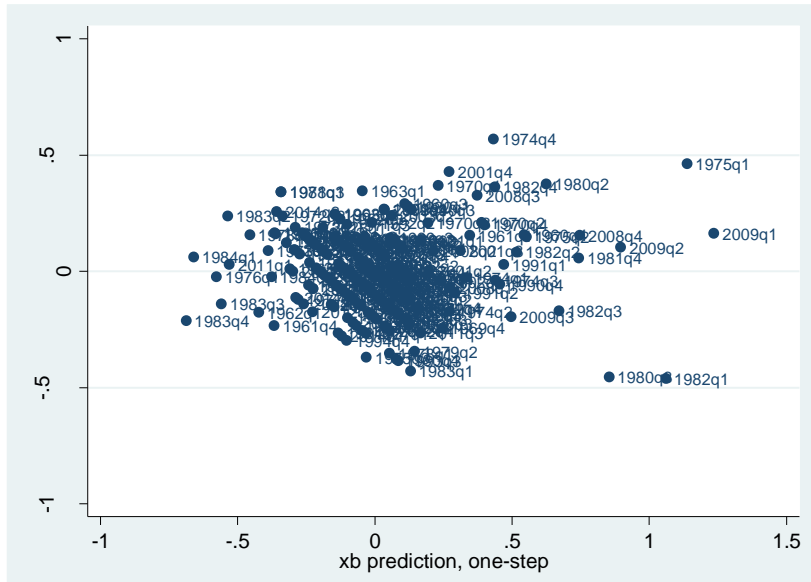

b. Model with one dummy (1975q1)

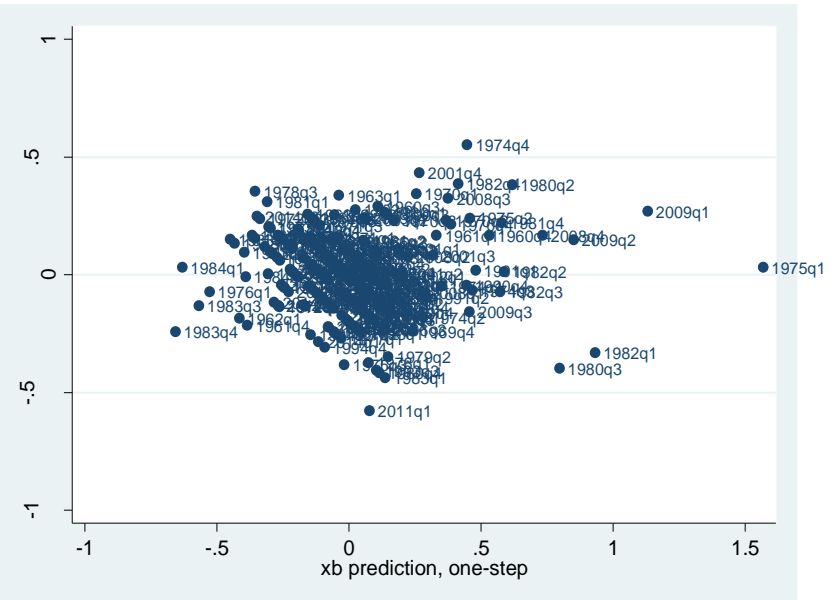

d. Model with two dummies (1975q1-2011q1)

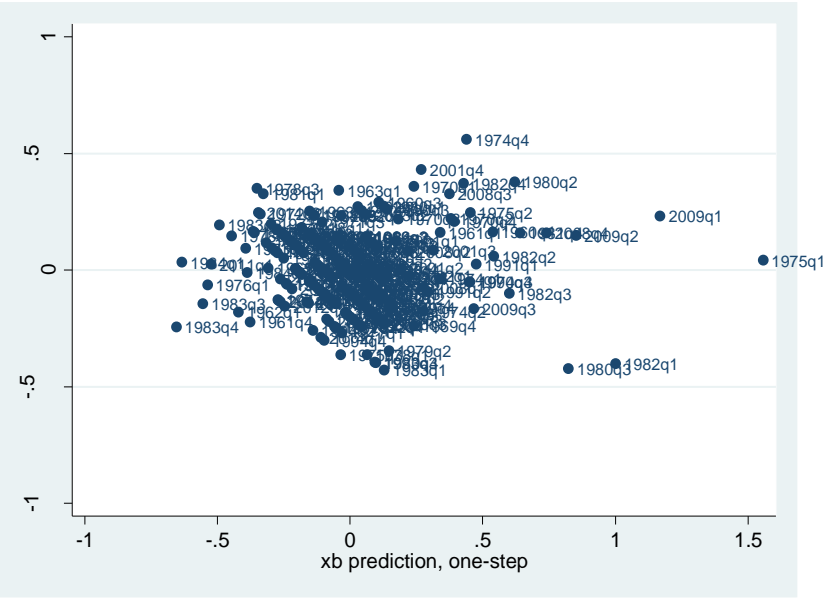

